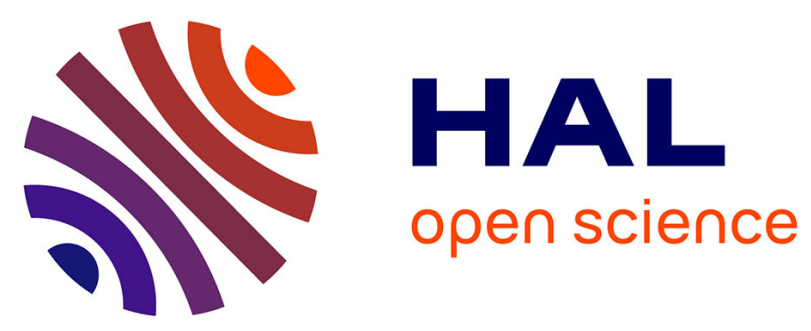

\title{
Modeling flow and heat transfer in a scraped surface heat exchanger during the production of sorbet
}

Oscar Darío Hernández-Parra, Artemio Plana-Fattori, Graciela Alvarez, Fatou-Toutie Ndoye, Hayat Benkhelifa, Denis Flick

\section{- To cite this version:}

Oscar Darío Hernández-Parra, Artemio Plana-Fattori, Graciela Alvarez, Fatou-Toutie Ndoye, Hayat Benkhelifa, et al.. Modeling flow and heat transfer in a scraped surface heat exchanger during the production of sorbet. Journal of Food Engineering, 2018, 221, pp.54-69. 10.1016/j.jfoodeng.2017.09.027 . hal-02079248

\section{HAL Id: hal-02079248 \\ https://hal.science/hal-02079248}

Submitted on 16 Dec 2020

HAL is a multi-disciplinary open access archive for the deposit and dissemination of scientific research documents, whether they are published or not. The documents may come from teaching and research institutions in France or abroad, or from public or private research centers.
L'archive ouverte pluridisciplinaire HAL, est destinée au dépôt et à la diffusion de documents scientifiques de niveau recherche, publiés ou non, émanant des établissements d'enseignement et de recherche français ou étrangers, des laboratoires publics ou privés. 
1 Modeling Flow and Heat Transfer in a Scraped Surface Heat Exchanger during the

\section{Production of Sorbet}

3

4 Oscar Darío Hernández-Parra (1), Artemio Plana-Fattori (2)(*), Graciela Alvarez (1),

$5 \quad$ Fatou-Toutie Ndoye (1), Hayat Benkhelifa (1)(2), Denis Flick (1)(2)

6

7 (1) IRSTEA, UR Génie des Procédés Frigorifiques, 92761 Antony Cedex, France

8

9 (2) UMR Ingénierie Procédés Aliments, AgroParisTech, INRA, Université Paris-Saclay, 1091300 Massy, France

11

$12(*)$ author corresponding address:

13 AgroParisTech, Dept. MMIP, 16 rue Claude Bernard, 75231 Paris CEDEX 5

14 E-mail: artemio.planafattori@agroparistech.fr 


\section{Introduction}

Scraped surface heat exchangers (SSHEs) are commonly found in the food industry as a way of controlling the heat transfer in products of high viscosity or that could lead to fouling on the internal walls. Many designs exist; they generally consist of a double pipe heat exchanger which contains a rotating element inside the inner pipe, where a number of blades are attached with the purpose of scraping the inner cylinder at every rotation (Rao and Hartel, 2006). One application for SSHEs has been the industrial production of ice cream-like desserts (e.g. sorbets), where the purpose of the SSHE is to chill and freeze a formulated mix in order to crystallize the water present on the walls of the inner pipe (Goff and Hartel, 2013; Rao and Hartel, 2006). The blades also serve in this case as a dispersion system for the ice formed and a certain amount of air that could be introduced into the product. Air bubbles and ice crystals sizes are major quality parameters in sorbets, and their occurrence is closely related to the heat transfer mechanism and the flow characteristics in the SSHE. Actually, complicated heat transfer mechanisms and very complex flow profiles take place in the SSHE as a result of the presence of rotating elements, of the crystallization phenomena, and of the product rheology (which is highly dependent on the ice fraction). The experimental analysis of flow characteristics and heat transfer mechanisms inside the SSHE, particularly during the production of frozen desserts, is onerous and technically difficult to carry out. This is a situation in which physics-based modeling can effectively be used as a tool for providing insight about relevant phenomena.

Flow through the inner pipe of SSHEs has been extensively studied experimentally for single-phase Newtonian and non-Newtonian fluids (e.g. Wang et al., 1999, 2000; Dumont et al., 2000a, 2000b; Yataghene et al., 2011; see also the reviews by Abichandani et al., 1986; Härröd, 1986; Rao and Hartel, 2006). In summary, the flow structure can be 
understood as an annular gap flow (i.e. Taylor-Couette) disturbed by the presence of rotor parts. Once a critical Taylor number value is reached, stable or wavy unstable forms of vortices begin to establish throughout the inner pipe. However, the flow patterns can be strongly affected by the rheological behavior of the fluid, the presence of blades in the system, their angle, and particularly, the gap (i.e. the clearance) between the tips and the inner wall. Large local shear rates are observed to appear in the clearance, as well as secondary vortexes in zones related to the blades. Modeling approaches have been developed to overcome the complex experimentation required, i.e. whether more precise investigation of flow phenomena or changes on the geometry of the blades make impractical the development of experimental facilities (e.g. Baccar and Abid, 1997, 1999; Stranzinger et al., 2001; Duffy et al., 2007; Yataghene et al., 2008, 2009, 2011; D'Addio et al., 2013; Yataghene and Legrand, 2013; Blasiak and Pietrowicz, 2016).

Numerous studies dealing with heat transfer phenomena in single-phase fluids in SSHEs have been reported (e.g. Härröd, 1986; Rao and Hartel, 2006). Experimental studies usually rely on obtaining the average heat transfer coefficient in the inner pipe of the exchanger; results are often expressed in terms of Nusselt number correlations in function of axial and rotational Reynolds as well as the Prandtl number, the number of blades, and geometrical ratios of diameters and lengths (e.g. Skelland, 1958; Trommelen et al., 1971; Abichandani et al., 1986; Boccardi et al., 2010). Numerical approaches have also been used to complement or develop heat transfer correlations (e.g. Baccar and Abid, 1997, 1999; Yataghene et al., 2009; Saraceno et al., 2011; D'Addio et al., 2013; Yataghene and Legrand, 2013; Rainieri et al., 2014; Dehkordi et al., 2015; Blasiak and Pietrowicz, 2016). The

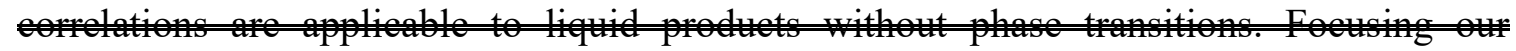


2y elear that these Nuselt number comations using the logathmic averame temate difference are no more applieable beatse temperame solution along the SSIE is

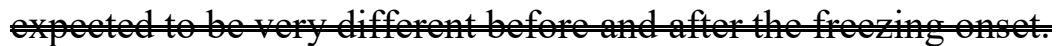

It is noteworthy that few experimental works deal with heat transfer in freezing solutions in SSHEs (e.g. Qin et al., 2003, 2006; Lakhdar et al., 2005; Martinez et al., 2014). In such cases, as freezing takes place, the apparent physical properties of the fluids change strongly and affect the heat transfer coefficient. For instance, Arellano et al. (2013b) have shown that the apparent viscosity of non-aerated sorbet can increase from 1 to $12 \mathrm{~Pa} \cdot \mathrm{s}$ along its pathway in the SSHE. Lakhdar et al. (2005) included the influence of initial non-freezing substance concentration in their heat transfer coefficient correlations. Simple equations for calculating the heat transfer coefficient during freezing of milk and aqueous glycerol mixtures which include a correction term for the ice heat of fusion can be found in the literature (e.g. Qin et al., 2003, 2006).

Mathematical models have also been developed specifically for SSHE ice cream production; we can identify classes of models associated with increasing degree of complexity about coupled phenomena. Bongers (2006) proposed a model considering the freezer barrel as a series of well mixed stages, taking into account four contributions to the energy balance: refrigeration, crystallization, dissipation of mechanical energy, and scraping friction of the blades on the ice layer. In a further development of this model, Dorneanu et al. (2009) have included conservation equations for selected dispersed phases (water, sugar, fat and remaining components); they considered an immobile frozen layer at the wall, and the plug-flow assumption for the mean axial flow. Lian et al. (2006) have 
combined a 2D computational fluid dynamics model and a population balance approach with the aim to predict the ice crystal size distribution in the final product.

Non-aerated lemon sorbet production has been studied in a series of articles by Arellano et al. (2013a, 2013b, 2013c), Gonzalez-Ramirez et al. (2013a, 2013b) and Casenave et al. (2013, 2014). Modeling efforts were devoted by those authors in predicting ice crystal size distributions. These models used residence time distributions and reduced heat transfer equations under transient operation with population balance approaches in order to predict crystal chord length distributions during steady-state operations. Particularly, the model developed by Arellano et al. (2013c) reached good agreement with experimental crystals mean chord lengths and temperature profiles along the exchanger. In such a goal, key parameters as global heat transfer coefficients, and crystal growth and nucleation rate constants, were adjusted in the model. Although the results show a good agreement, the reduced models cannot offer a full insight into the heat transfer mechanisms taking place inside the exchanger.

In the logical continuation of experimental and modeling efforts devoted by Arellano et al. (2013a, 2013b, 2013c), this study presents a numerical model for predicting the non-aerated lemon sorbet production in a pilot-scale SSHE under different operating conditions. The main objectives were: firstly, to implement a 3D computational fluid dynamics (CFD) model for solving the coupled problem of fluid flow and heat transfer within the SSHE, while respecting the strong influence of temperature on key properties of the liquid food product; secondly, to analyze the 3D distributions of key variables throughout the SSHE, at scales beyond usual experiments; and lastly, to assess the performance of this model under different operating conditions, using as reference measurements conducted in those early contributions. 


\section{2. Development of the model}

113

\subsection{Physical problem description}

115 Before developing the model equations, a short description of the physical problem is

116 required. The modeling approach could be applied to the production of non-aerated sorbet

117 in any SSHE freezer; here it was implemented for the pilot unit used by Arellano et al.

118 (2013a, 2013b, 2013c). Those authors carried out the freezing of a commercial UHT-

119 pasteurized lemon sorbet $\operatorname{mix}(14.6 \% \mathrm{w} / \mathrm{w}$ sucrose, $8 \% \mathrm{w} / \mathrm{w}$ fructose, $0.09 \% \mathrm{w} / \mathrm{w}$

120 dextrose, $3 \% \mathrm{w} / \mathrm{w}$ lemon juice concentrate 60 Brix, $0.5 \% \mathrm{w} / \mathrm{w}$ locust bean gum/guar gum/

121 hypromellose stabilizer blend) in a laboratory scale continuous pilot freezer (WCB Model

122 MF 50). Within the freezer, the SSHE consists of a double pipe heat exchanger whose inner

123 pipe ( $0.05 \mathrm{~m}$ inner diameter, $0.40 \mathrm{~m}$ long) contains a solid flattened cylindrical rotor

124 equipped with two scraper blades placed at opposite positions. A scheme of the SSHE is

125 presented in Figure 1.

126 Four wireless data loggers with built-in temperature sensors (Thermochron iButton

127 DS1922L - Maxime; $16.3 \mathrm{~mm}$ diameter and $6.4 \mathrm{~mm}$ thick, calibrated to an accuracy of

$128 \pm 0.2{ }^{\circ} \mathrm{C}$ within a range from -20 to $20{ }^{\circ} \mathrm{C}$ ) were placed at regular distances on the flat

129 dasher surface as viewed in Figure 1B. Also, a calibrated type T thermocouple (accuracy of

$130 \pm 0.2{ }^{\circ} \mathrm{C}$ ) was placed at the entrance of the heat exchanger, and a calibrated Pt100 probe

131 (Baumer, accuracy of $\pm 0.1^{\circ} \mathrm{C}$ ) was placed at the outlet pipe of the exchanger. These probes

132 allowed the measurement of temperature during steady-state operation of the freezer. 
133 The processing unit has a nominal capacity of 25 to $75 \mathrm{~kg} / \mathrm{h}$ (about 0.007 to $0.021 \mathrm{~kg} / \mathrm{s}$ ),

134 with accuracy of $\pm 9 \times 10^{-5} \mathrm{~kg} / \mathrm{s}$. Refrigerant fluid was evaporating dichlorodifluoromethane 135 (R22), which circulated through the cooling outer pipe of the SSHE at controlled 136 temperature. This temperature was measured through a calibrated type-T thermocouple, 137 with an accuracy of $\pm 0.2{ }^{\circ} \mathrm{C}$, fixed with conductive aluminum tape on the external surface

138 wall of the outer pipe. The rotational speed of the dasher and blades varied from 545 to

$1391000 \mathrm{rpm}$ (about 9 to $17 \mathrm{rev} / \mathrm{s})$, with accuracy of $1 \mathrm{rpm}$ (about $0.017 \mathrm{rev} / \mathrm{s}$ ).

140 Using this device, Arellano et al. (2013a) measured the fluid temperature at selected 141 positions inside the SSHE under seven combinations of operating conditions, using three 142 refrigerant temperatures $\left(T_{R}=-10.6^{\circ} \mathrm{C},-15.3^{\circ} \mathrm{C}\right.$ and $\left.-20.1^{\circ} \mathrm{C}\right)$, three mass flow rates $143\left(\dot{m}_{m i x}=25,50\right.$ and $\left.75 \mathrm{~kg} / \mathrm{h}\right)$ and three dasher rotation frequencies $\left(f_{\text {rot }}=545,750\right.$ and 1000 $144 \mathrm{rpm})$. In all cases the sorbet mix inlet temperature was held constant at $5{ }^{\circ} \mathrm{C}$.

\subsection{Governing equations}

147 Although non-aerated sorbets are two-phase systems containing ice and concentrated liquid 148 mix, in this work it is assumed that sorbet mix and freezing sorbet can be treated as a 149 single-phase fluid with apparent physical properties varying with temperature; hence mass, 150 momentum and energy conservation equations for single-phase fluids were used, following 151 the approach proposed by Lakhdar et al. (2005). The inner cylinder and the rotating 152 elements are the most relevant parts in the SSHE, and therefore, it is convenient to establish 153 the governing equations using a reference frame rotating with them since that allows deal 154 with a non-moving geometry. From this, a relative velocity in the moving frame, $\vec{v}$, can be 155 defined from the velocity in the Galilean frame, $\vec{u}$, such that: 
157 and the conservation equations for mass, momentum and energy can be expressed as:

$\vec{\nabla} \bullet \vec{v}=0$

$\rho(\vec{v} \bullet \vec{\nabla}) \vec{v}=-\vec{\nabla} \bullet \overline{\bar{\tau}}-\vec{\nabla} p-2 \rho\left(\vec{\Omega}_{\text {rotor }} \times \vec{v}\right)-2 \rho\left(\vec{\Omega}_{\text {rotor }} \times \vec{\Omega}_{\text {rotor }} \times \vec{r}\right)$

$160 \rho C_{p} \vec{v} \bullet \vec{\nabla} T=\vec{\nabla} \bullet(k \vec{\nabla} T)-(\overline{\bar{\tau}}: \vec{\nabla} \vec{v})$

161 where $\vec{v}$ is the velocity (magnitude in $\mathrm{m} / \mathrm{s}$ ), $\overline{\bar{\tau}}$ the viscous stress tensor obtained from a

162 power-law model, $p$ the pressure $(\mathrm{Pa})$, and $T$ the temperature $(\mathrm{K}) ; \rho$ is the product

163 density $\left(\mathrm{kg} \cdot \mathrm{m}^{-3}\right), C_{p}$ its specific heat capacity $\left(\mathrm{J}_{\mathrm{kg}}{ }^{-1} \cdot \mathrm{K}^{-1}\right)$, and $k$ its thermal conductivity

$164\left(\mathrm{~W} \cdot \mathrm{m}^{-1} \cdot \mathrm{K}^{-1}\right)$.

165 Since the internal dasher and the blades occupy a non-negligible portion of the volume

166 inside the inner pipe in the heat exchanger, it is possible that heat conduction in the solids

167 affects the temperature profiles in the fluid. In other works this has been sometimes

168 neglected (Lian et al., 2006; Yataghene et al., 2009) or included (Yataghene and Legrand,

169 2013). In the present work, heat transfer across the dasher and blades were included while

170 dasher and blade supports were neglected; the influence of heat conduction in the dasher

171 and the blades is assessed through numerical simulation while that associated with their

172 supports remains a matter of discussion (see subsection 5.2). Under the rotating reference

173 frame, both elements (dasher and blades) appear static, and therefore, the following

174 equation holds for the heat transfer:

$175 \vec{\nabla} \bullet(k \vec{\nabla} T)=0$

176 The following boundary conditions were considered for solving fluid flow equations: 
a) Under the rotating reference frame: the inner wall of the internal cylinder, the inlet and outlet bowls and pipes were perceived to be rotating at the speed of the rotor on the opposite sense of rotation; hence the non-slip condition in these surfaces becomes $\vec{v}=-\vec{\Omega}_{\text {rotor }} \times \vec{r}$

b) On the dasher and blades surfaces: $\vec{v}=0$ (no-slip condition).

c) At the inlet boundary: laminar flow profile was imposed from the specified mass flow rate and the rheology of the sorbet mix:

$v_{x}=\Omega_{\text {rotor }} y ; \quad v_{y}=-\Omega_{\text {rotor }} x ; \quad v_{z}=\frac{3 n+1}{n+1} \frac{\dot{m}_{\text {mix }}}{\rho \pi r_{\text {pipe }}^{2}}\left(1-\left(\frac{r}{r_{\text {pipe }}}\right)^{\frac{n+1}{n}}\right)$ where $n$ is the flow behavior exponent. d) At the outlet boundary, the same flow profile was re-imposed to insure mass conservation.

190 The following boundary conditions were considered for solving the equation of

191 conservation of energy:

192 a) The product was assumed to enter in the inlet pipe of the SSHE at a uniform $193 \quad$ temperature of $5{ }^{\circ} \mathrm{C}$.

194 b) At exit the outlet pipe of the SSHE, a null gradient was assumed for the product temperature. 
c) The product was assumed to flow under adiabatic conditions in the inlet and outlet pipes as well as in the inlet and outlet bowls of the SSHE: these computational subdomains were assumed to be delimited by thermally-insulated walls. d) Inside the SSHE cylinder, the product flows confined between the wall, the dasher and the blades. Conduction is solved throughout these solid elements; at the interface between product and dasher or blades, continuity of temperature and heat flux was assumed.

e) At the internal wall of the SSHE inner cylinder, the heat flux density was expressed $\underline{\text { as the product of a global heat transfer coefficient }}(U)$ and the difference between the $\underline{\text { refrigerant evaporating temperature }\left(T_{R}\right) \text { and the liquid product temperature in }}$ contact with the wall $\left(T=T_{\text {inside }}\right.$ (see Figure 2):

$\underline{U\left(T_{R}-T\right)=k \vec{\nabla} T \cdot \vec{n}}$

We applied the value $U=2500 \mathrm{~W} \cdot \mathrm{m}^{-2} \cdot \mathrm{K}^{-1}$ reported by Arellano et al. (2013c). This heat transfer coefficient is associated with a) convection between the refrigerant fluid and the external side of the SSHE inner cylinder, which is characterized by the outside convective heat transfer coefficient $h_{\text {outside }}$, and b) conduction through the stainless steel wall which separates the refrigerant fluid and the product inside the

213 SSHE inner cylinder; the wall is characterized by thickness $e_{w}=0.002 \mathrm{~m}$ and

214 conductivity $k_{w}=15 \mathrm{~W} \cdot \mathrm{m}^{-1} \cdot \mathrm{K}^{-1}$. This way, $\underline{U}$ can be expressed as:

$$
U=\frac{1}{\frac{e_{w}}{k_{w}}+\frac{1}{h_{\text {outside }}}} .
$$


The SSHE inner cylinder was not included in the computational domain because, in the reference frame of the blades, it is in rotation; hence the problem would become unsteady. The heat transfer resistance of the wall $\left(e_{w} / k_{w}\right)$ represents one third of the $\underline{\text { total resistance } 1 / U}$. An upper limit for the global heat transfer coefficient in our problem would be $U=k_{w} / e_{w} \approx 7500 \mathrm{~W} \cdot \mathrm{m}^{-2} \cdot \mathrm{K}^{-1}$, which can be estimated by neglecting the convective heat transfer resistance between the external side of the SSHE inner cylinder and the refrigerant fluid $\left(1 / h_{\text {outside }}\right)$ in equation (8).

3. Product physical properties

Physical properties of sorbets were estimated from experimental measurements or from available information in the literature. Some approximations were performed in order to reduce the mathematical difficulty of solving the governing equations. Table 1 summarizes values and correlations assumed.

\subsection{Freezing point curve of concentrated lemon sorbet mix and sorbet ice fraction}

231 Although non-aerated sorbets are two-phase systems containing ice and concentrated liquid

232 mix, in this work it is assumed that the apparent physical properties can be approximated 233 assuming that a local thermodynamical equilibrium is established at any point of the fluid 234 inside the SSHE. This approach has been also used before in order to simulate similar 235 systems e.g. ice crystallization from sugar solutions (Lakhdar et al., 2005) and ice cream 236 properties estimation (Cogné et al., 2003). At equilibrium, the solute fraction (in the liquid 237 surrounding the ice crystals) becomes that of the freezing point curve of concentrated 238 sorbet mix at the local temperature. 
239 Data of freezing point temperatures for the commercial lemon sorbet mix modeled in this 240 work were obtained experimentally by Gonzalez-Ramirez (2012), who proposed a 241 polynomial correlation restricted to the range from $-13{ }^{\circ} \mathrm{C}$ to $0{ }^{\circ} \mathrm{C}$ whereas the sorbet 242 temperature can be as low as $-20^{\circ} \mathrm{C}$. To improve the predictions, a correlation based on a 243 thermodynamical approach was developed. Freezing point depression curves of 244 thermodynamically ideal binary solutions of a freezing solvent compound (i.e. water) and a 245 solute (i.e. soluble solids) can be expressed; their molar fraction being a function of 246 temperature, solvent pure compound heat of fusion at its melting point temperature, solvent 247 liquid and solid heat capacities as follows:

$$
\ln x_{w}(T)=\frac{\Delta h_{f, m p}}{R}\left(\frac{1}{T_{m p}}-\frac{1}{T}\right)-\frac{1}{R}\left(\int_{T_{m p}}^{T} \frac{c_{p, w}-c_{p, i}}{T} d T^{\prime}-\int_{T_{m p}}^{T} \frac{c_{p, w}-c_{p, i}}{T^{\prime}} d T^{\prime}\right)
$$

249 The solute mass fraction can be expressed in function of the water molar fraction:

$$
250 \quad w_{S}^{*}(T)=\frac{1-x_{w}(T)}{1-C x_{w}(T)}
$$

251 where $C=1-M_{w} / M_{s}$ could be regarded as a fitting parameter depending on the molar 252 mass of water and of solute. In order to improve the quality of the fitting curve, a second 253 constant was introduced, and the equation fitted was:

$$
w_{S}^{*}(T)=C_{1} \frac{1-x_{w}(T)}{1-C_{2} x_{w}(T)}
$$

255 In equation (9) the heat capacities of liquid water and ice were taken as functions of 256 temperature according to Choi and Okos (1986). After fitting the experimental data to 257 equation (11) the values obtained were $C_{1}=0.7316$ and $C_{2}=0.9476$. Figure 3 displays 258 experimental data and corresponding results from equation (11) for two products: concentrated lemon sorbet mix and sucrose solution. 
260 Once the equilibrium solute concentration is determined, a mass balance yields the ice mass

261 fraction using the initial solute fraction in the mix, as indicated in equation (12). The 262 estimated ice fractions at different temperatures are shown in Figure 4A.

$263 w_{i}=1-\frac{w_{s} 0}{w_{s}^{*}}$

\subsection{Density}

266 The sorbet density was estimated from the ice mass fraction and the specific densities of ice 267 and mix at temperatures ranging from -20 to $10{ }^{\circ} \mathrm{C}$ using the approach recommended by 268 Choi and Okos (1986). Estimated values of density vary slightly (less than $6 \%$ ) and the constant value $1050 \mathrm{~kg} \cdot \mathrm{m}^{-3}$ was assumed for modeling purposes.

\subsection{Rheological behavior of non-aerated lemon sorbet}

Arellano et al. (2013b) have thoroughly investigated the influence of the temperature and thus of the ice volume fraction on the apparent viscosity of sorbet by using pipe rheometry measurements. Their main results can be summarized by an empirical rheological powerlaw model which predicts the consistency index and the flow behavior index as function of the ice volume fraction and the temperature, these two parameters being linked by the 277 hypothesis of local equilibrium.

278 The difficulty to study the sorbet rheological behavior is put in evidence in Figure 2 of 279 Arellano et al. (2013b): the range of shear rates permitting reliable observations decreases 280 as the sorbet becomes colder and associated with higher ice volume fraction. Indeed, at $281-2.89^{\circ} \mathrm{C}$ (ice volume fraction of $5.8 \%$ ), the observations were reliable for shear rates up to 282 about $450 \mathrm{~s}^{-1}$; at $-5.68{ }^{\circ} \mathrm{C}$ (ice volume fraction of $39 \%$ ), the observations were reliable for 
283 shear rates up to $40 \mathrm{~s}^{-1}$ only. The rheological model proposed by those authors represents a 284 synthesis over the whole dataset of operating conditions studied (mass sorbet flow rate and 285 sorbet temperature).

286 The following approximation was fitted to describe the consistency index (in units of Pa.s ${ }^{\mathrm{n}}$ )

287 of both sorbet mix and sorbet:

$288 K=0.5838 \quad$ for $T \geq T_{\text {if }}$

$289 K=0.5838+10.16\left(T_{i f}-T\right)$ for $T<T_{i f}$

290 where $T_{i f}=-2.72{ }^{\circ} \mathrm{C}$ is the initial freezing temperature. Figure $4 \mathrm{~B}$ compares equation (13)

291 with the consistency index estimated accordingly to Arellano et al. (2013b) at selected 292 temperatures. Applying the local thermodynamical equilibrium assumption as discussed 293 above between -20 and $10^{\circ} \mathrm{C}$, the sorbet flow index $(n)$ reported by Arellano et al. (2013b) 294 ranges between 0.38 and 0.55 . In this work a constant value of 0.5 was used for modeling 295 purposes.

\subsection{Apparent heat capacity}

298 In order to include the effect of water freezing into the enthalpy of the sorbet, the apparent

299 heat capacities of the sorbet mix and the frozen non-aerated sorbet were estimated using the 300 approach proposed by Cogné et al. (2003) for ice cream and by Lakhdar et al. (2005) for 301 crystallizing sugar solutions. It consists of a weighted average between the values for mix 302 and ice, including a correction term for the change in the amount of ice according to the 303 local thermodynamical equilibrium approximation:

$304 C_{p}=C_{p i} w_{i}+C_{p s} w_{s}+C_{p w}\left(1-w_{i}-w_{s}\right)-\Delta H_{f} \frac{d w_{i}}{d T}$ 
305 In order to simplify the heat capacity calculation, the following equation was fitted from

306 estimation:

$C_{p}=3266+7.95 \times 10^{4} \exp \left(0.543\left(T-T_{i f}\right)\right)$ for $T<T_{i f}$

309 Figure 4C compares estimated values provided by equations (14) and (15).

\subsection{Thermal conductivity}

312 Non-aerated sorbet was represented as by Cogné et al. (2003) as a two-phase material, 313 which consist of a solid phase (ice crystals) dispersed in a continuous fluid phase made of 314 dry matter and unfrozen water (Maxwell-Eucken model). The thermal conductivity of the continuous phase was estimated by using the intrinsic thermal conductivity values of each main components and their volume fractions estimated from their weight fraction and their density (Choi and Okos, 1986). In the present study, the solute mass fractions were obtained from equation (10). As before, a simpler equation was fitted:

$k=0.432+0.303\left(1-\exp \left(-0.367\left(T_{i f}-T\right)\right)\right)$ for $T<T_{i f}$

321 A comparison between estimated values and equation (16) is shown in Figure 4D.

\section{Numerical model}

\subsection{Geometry}

326 In order to avoid a computationally-intensive transient 3D simulation with moving 327 boundaries, we adopt here the geometrical representation of the SSHE which is displayed in 
328 Figure 1A. While being quite simple, this representation allows us to conduct a steady-state 329 simulation of all the relevant phenomena occurring in the cylindrical section of the SSHE: 330 scraped surfaces, dasher, and blades.

331 The inner cylinder of the SSHE under consideration contains several elements: i) the sorbet 332 that is subjected to heat transfer and flow, ii) the internal solid elements that constitute the 333 rotor (i.e. the dasher, the blades and their supports), and iii) the temperature sensors added 334 to the dasher. Dasher and blades were considered for simulations given their major 335 influence on the global performance of SSHEs; nevertheless, the blade supports and 336 temperature sensors were not included since they have a relative small size and hence a 337 expected negligible influence on flow profiles as well as on heat transfer mechanisms. Both 338 headers of the exchanger contain reservoirs for the fluid entering or leaving the inner 339 cylinder, as well as the dasher supports and the mechanical joins required. They were 340 simplified, as shown in Figure 5, replacing them by co-axial cones of $0.01 \mathrm{~m}$ length 341 connecting the inner cylinder of the SSHE to the inlet and outlet pipes. Also, in the 342 exchanger the mix enters the bowl laterally, while the sorbet exits downwards. This was 343 simplified by using co-axial horizontal tubes of $0.0125 \mathrm{~m}$ diameter, and $0.1 \mathrm{~m}$ long for 344 ensuring a complete development of flow profiles.

345 Although the gaps between the blades and the wall of the internal cylinder have been 346 shown to have an effect on the flow patterns inside SSHEs with liquid flow (Dumont et al., $3472000 \mathrm{a}, 2000 \mathrm{~b}$ ), they were neglected in this work by extending the blades up to the inner 348 wall of the internal cylinder. This was made considering that ice formation takes place 349 mostly on the inner wall of the internal cylinder during the production of ice creams and 350 sorbets and the action of the scraping blades on this ice could block the gap from the fluid 351 (Cook and Hartel, 2010). 


\section{4.2. Mesh construction}

354 Looking for the resolution of equations which govern the coupled phenomena, every 355 computational domain has to be subdivided into a number of small, non-overlapping cells.

356 The mesh was constructed using the COMSOL Multiphysics integrated builder, version

357 5.2. In order to account correctly for the momentum and thermal boundary layers, the mesh 358 around the surfaces was built using four-element layer of prismatic elements, while the 359 domain interiors were filled out with tetrahedral elements of varying minimum sizes.

360 Results achieved with the mesh constituted by $1.5 \times 10^{6}$ elements provide a satisfactory level 361 of reliability in terms of the predicted profile of temperature along the SSHE axis, as 362 indicated by a comparison with two other meshes (see subsection 5.3). Figure 6 displays 363 this mesh around the dasher and the blades, as well as a cut view at $z=0.2 \mathrm{~m}$.

\section{4.3. Calculation strategy}

366 The solution of the linear system resulting from the linearization of the governing equations 367 is reached through the Parallel Sparse Direct Linear Solver (PARDISO) (Schenk and 368 Gartner, 2004), as implemented with the finite-elements method in the simulation package 369 COMSOL Multiphysics, version 5.2 (Zimmermann, 2006), Satisfactory convergence of 370 numerical solutions was reached after hundreds of iterations, looking for a relative 371 tolerance better than $10^{-5}$. Simulations were implemented in a PC station with $6 \mathrm{CPU}$ at $372 \quad 3.50-\mathrm{GHz}$ and 128-Gb RAM.

373 The coupled problem to be solved is challenging from different perspectives: on one hand, 374 the product is characterized by physical properties which vary significantly with 375 temperature; on the other hand, the product experiences a complex flow pattern, including 
obstructions and relatively fast rotation. The mathematical solution associated with every operating condition of interest was obtained as the result of a particular step-by-step calculation strategy. Firstly, preliminary fields for velocity and pressure were estimated at the temperature $5{ }^{\circ} \mathrm{C}$, by solving equations (2-3); secondly, a preliminary temperature field was estimated for that preliminary fluid flow field by solving only equations (4-5); finally, assuming these first-guesses as starting condition, the ensemble of coupled equations (2-5) was solved simultaneously by a direct method, iteratively, while increasing the maximal value for the sorbet consistency index, until no further increase influenced the mathematical solution.

\section{Results and discussion}

\subsection{Analysis of flow and temperature profiles}

Main features of fluid flow in the SSHE as predicted by the numerical model are displayed in Figure 7. These results were obtained under the reference operating conditions $\dot{m}_{\text {mix }}=$ $50 \mathrm{~kg} / \mathrm{h}, T_{R}=-15.3^{\circ} \mathrm{C}$ and $f_{\text {rot }}=750 \mathrm{rpm}$. The rotation direction of the inner wall of the heat exchanger is clockwise as seen from the exit of the outlet pipe.

Firstly, the velocity field is largely dominated by rotation: the highest velocities occur in the vicinity of the exchanger wall, and the maximal tangential velocity $(1.97 \mathrm{~m} / \mathrm{s})$ is about 200 times higher than the mean axial velocity (about $0.01 \mathrm{~m} / \mathrm{s}$ ).

Secondly, the flow is confined between the exchanger wall, the dasher and the blades; as a consequence, changes of velocity direction are significant. The region indicated by the red ellipse in Figure 7 puts in evidence the occurrence of recirculation in the vicinity of the 
blades endings. Indeed, the occurrence of recirculation near the blades endings has been

400 predicted by mathematical modeling of fluid flow in scraped surface heat exchangers 401 (Duffy et al., 2007). Fluid parcels travelling between the dasher and the blades near the exchanger outlet are reoriented back towards the exchanger inlet, following pathways between the blades and the wall. The reciprocal feature takes place near the exchanger inlet, where parcels coming between the dasher and the blades are reoriented back towards the exchanger outlet, between the blades and the wall. Such features are particularly important for the temperature axial distribution, because they foster mixing between fluid parcels experiencing different thermal histories. Indeed, near the exchanger inlet, colder parcels travelling between the dasher and the blades do encounter relatively warmer parcels just 409 coming from the entrance of the inlet pipe (at $5^{\circ} \mathrm{C}$ ), allowing a faster decrease of 410 temperature than we might expect without such a recirculation.

411 Figures $8 \mathrm{~A}$ to $8 \mathrm{C}$ display the velocity, pressure and temperature profiles in the SSHE as 412 predicted by the numerical model under the operating conditions $\dot{m}_{m i x}=50 \mathrm{~kg} / \mathrm{h}, T_{R}=$ $413-15.3{ }^{\circ} \mathrm{C}$ and $f_{\text {rot }}=750 \mathrm{rpm}$. In the left-hand side of Figures $8 \mathrm{~A}, 8 \mathrm{~B}$, and $8 \mathrm{C}$, as well as in 414 Figures $8 \mathrm{D}$ and $8 \mathrm{E}$, the product flows from the left to the right, as indicated by the vector 415 velocity in the inlet and the outlet pipes in Figure 8B.

416 From the rotating reference frame, the inner cylinder wall is perceived turning clockwise 417 (right-hand side of Figures 8A, 8B, and 8C); the liquid flows from the annular space left by 418 the dasher (point 1) towards the zone near the lower face of the blade (point 2). In this zone, 419 the high-speed flow is blocked suddenly by the lower surface of the blade and immediately 420 forced to change direction. This momentum accumulation yields a pressure increase in this 421 region, whose maximum occurs where the blade encounters the wall. The region on the 
opposite side of the blade (point 6) experiences the opposite phenomena, with the pressure 423 reaching its lowest value at the contact between the blade and the wall. These trends can be appreciated in the cross-section view of the pressure field in Figure 8B. Therefore, from point 2, the fluid is forced to follow the lower surface of the blade (point 3), get around it (point 4) and follow the upper side of the blade (point 5) towards point 6 . From there, the rotating wall forces the flow to change direction drastically (point 7) leading the fluid back to the opposite annular section (point 1') where the sequence described before is repeated following the symmetry in the SSHE. It is noteworthy that the entire trajectory is carried out 12.5 times per second (for $f_{\text {rot }}=750 \mathrm{rpm}$ ).

431 The longitudinal view in the pressure profile shown in Figure 8B also indicates the axial 432 flow direction in the SSHE. It can be observed that, inside the SSHE between the dasher 433 and the blades (high-pressure zone, point 9), pressure increases from the inlet pipe towards 434 the outlet pipe, reaching a maximum before the blades ending $(z \sim 0.36 \mathrm{~m})$. This forces the 435 fluid in this zone to go back to the exchanger inlet promoting back-mixing. Between the 436 blades and the wall (low-pressure zone, point 10) the opposite effect (decreasing pressure) 437 directs the flow towards the outlet pipe. Near the blades ending $(z>0.36 \mathrm{~m})$, where the 438 pressure gradients are inversed, a recirculation zone is observed (point 11), as displayed in 439 Figure 7.

440 The range of shear rate conditions in the SSHE is wide, actually from zero up to more than $4412000 \mathrm{~s}^{-1}$. On one hand, as suggested by the blue regions in the shear rate display of Figure $4428 \mathrm{~A}$, the velocity field can exhibit quite "gentle" features (e.g. between the dasher and one 443 blade), being associated with relatively low shear. On the other hand, shear rates are very 444 high near the region where the blades touch the inner wall of the SSHE. 
445 The volume-averaged value of the shear rate in the SSHE can indicate the typical shear 446 conditions experienced by the sorbet while it undergoes progressive freezing. Considering 447 the heat exchanger itself only, without the inlet and the outlet cylindrical pipes and bowls 448 (see Figure 1A), the volume-averaged shear rate was about $420 \mathrm{~s}^{-1}$. We are aware that such 449 a value is near the higher limit of shear rates observed in the experiments conducted by 450 Arellano et al. (2003b) (see section 3). The application of the rheological model developed 451 by those authors is assumed to be satisfactory in most of the volume of the SSHE. 452 Nevertheless the lack of rheological data at high shear rate could impact the accuracy of 453 velocity prediction in the region where the blades touch the inner wall of the SSHE.

454 The temperature profile in the exchanger is presented in Figure 8C. At the entrance of the 455 inlet pipe, the temperature was assigned to $5{ }^{\circ} \mathrm{C}$, following the experimental conditions in 456 Arellano et al. (2013a). It can be observed a sharp temperature decrease in the entrance 457 region of exchanger, down to the initial freezing temperature of the sorbet mix $\left(-2.72{ }^{\circ} \mathrm{C}\right.$, $458 w_{\text {ice }}=0$ ). Such a decrease is most likely due to the inlet recirculation and the back-mixing 459 observed between dasher and blade, which puts into contact frozen sorbet from the mid460 section with the warmer fluid coming from the inlet pipe.

461 Once the initial freezing temperature is reached, the temperature decreases more slowly 462 with the axial coordinate. This could be explained by the higher energy required to freeze 463 the sorbet mix once passed the initial freezing temperature, which can be better appreciated 464 following the specific enthalpy of the sorbet presented in Figure 8D. It can be seen how 465 inside the SSHE freezing an additional $5 \%$ of the sorbet mass required about the same 466 amount of energy regardless of the location inside the exchanger. 
Also, as a consequence of the predominant tangential component of the velocity and the

468 fluid complex trajectory, the temperature variations in cross sections across the exchanger 469 were found to be very small (less than $0.2{ }^{\circ} \mathrm{C}$ ) suggesting a strong radial mixing. The fluid cooled at the wall is carried out around the blades and mixed with the slightly warmer fluid

471 in the zone between the blades and the exchanger wall.

472 Globally, the cooling effect of the scraped wall is thwarted by viscous dissipation effects.

473 The later are the highest in the exit area, given that the lower the temperature the higher the 474 consistency index, and so the apparent viscosity of the sorbet. Viscous dissipation profiles 475 are shown in Figure 8E. As discussed above, the increased presence of ice because of lower 476 temperatures increases the viscous dissipation near the end of the SSHE. Also, viscous 477 dissipation is caused by the friction of fluid changing direction radically (i.e. near the point 478 4) or friction with the solid elements in the exchanger, therefore on the dasher surface (i.e. 479 point 1) or around the blades (i.e. points 3-6).

\subsection{Comparison between experimental and simulated values}

The experimental verification of numerical model predictions represents a complicated task in the case of coupled problems of rotating flow, heat transfer and product transformation. Model predictions of isothermal fluid flow without product transformation in SSHE have been compared with observations gathered through noninvasive techniques, like Magnetic Resonance Imaging with nonmagnetic and nonmetal exchangers (Wang et al., 1999), and Particle Image Velocimetry with exchangers with transparent walls (Stranzinger et al., 2001; Crespi-Llorenz et al., 2016). These techniques cannot be applied to the SSHE here considered, whose walls are made of steel. The reliability of our modeling approach is

490 hereafter assessed by comparing temperature predictions with in situ observations which 
491 were performed while running the SSHE. The interest on the temperature field can be 492 justified by its determinant role on product transformation, and therefore on product 493 rheology. Arellano et al. (2013a) have successfully employed wireless temperature sensors 494 in order to monitor the temperature profile inside the SSHE under a variety of operating 495 conditions; forthcoming paragraphs consider these measurements in assessing the bulk 496 reliability of model predictions. Pressure drop measurements are unfortunately not 497 available.

498 Figure 9 compares Arellano et al. (2013a)'s measurements (indicated by circles) with the 499 temperature profile in the SSHE as predicted by the numerical model (black lines) under 500 the operating conditions $\dot{m}_{m i x}=50 \mathrm{~kg} / \mathrm{h}, T_{R}=-15.3^{\circ} \mathrm{C}$ and $f_{\text {rot }}=750 \mathrm{rpm}$. The left-most 501 circle indicates the temperature $5{ }^{\circ} \mathrm{C}$ prescribed at the entrance of the inlet pipe, upstream 502 to the heat exchanger; the right-most circle indicates the temperature value observed at the 503 exit of the outlet pipe, downstream to the heat exchanger. All the other four measurements 504 correspond to positions inside the heat exchanger (see Figure 2 of Arellano et al., 2013a). 505 The black line in displays $8 \mathrm{~A}$ and $8 \mathrm{~B}$ show temperature predictions obtained after setting to $50615 \mathrm{~W} \cdot \mathrm{m}^{-1} \cdot \mathrm{K}^{-1}$ the thermal conductivity of solids, and setting to $2500 \mathrm{~W} \cdot \mathrm{m}^{-2} \cdot \mathrm{K}^{-1}$ the heat 507 transfer coefficient at the SSHE inner wall. Such a thermal conductivity is typical of 508 stainless steel employed in food processing units, while this heat transfer coefficient value 509 was estimated by Arellano et al. (2013c) after energy balance considerations and closure 510 experiments conducted with the SSHE. Four results emerge from this comparison.

511 Firstly, the experimental temperature at the first measuring position inside the exchanger 512 inlet $(z=0.045 \mathrm{~m})$ is under-estimated by the model; actually, this was the case for all the 513 operating conditions considered in our study (see below). In the real SSHE pilot unit, as 
514 displayed in Figures 5A and 5B, the dasher is in contact with its support at the inlet bowl 515 (the header), which in turn is in contact with fresh mix at higher temperature. This could 516 lead to a non-negligible conductive heat transfer to the dasher, eventually reaching the temperature sensor. The predicted temperature profile cannot incorporate this phenomenon because the numerical model does not include the dasher supports.

519 Secondly, model predictions of the temperature profile follow the experimental temperature 520 at the second, third and fourth measuring positions inside the SSHE: differences reach $521+/-0.2{ }^{\circ} \mathrm{C}$, with no systematic sign. The temperature sensors are in contact with the dasher 522 while being submerged in a liquid product which becomes colder towards the exchanger 523 outlet.

524 Thirdly, the averaged value of the temperature at the exit of the outlet pipe $\left(-5.1^{\circ} \mathrm{C}\right)$ agrees 525 relatively well with the available measurement $\left(-4.6^{\circ} \mathrm{C}\right)$. Such a level of agreement can be 526 considered as satisfactory, given the sensibility of temperature predictions with respect to 527 model parameters (see below) and the influence of phenomena potentially affecting the 528 product temperature at the measuring position which were not included in the numerical 529 model (like conduction through dasher supports).

530 Lastly, the initial freezing temperature constitutes a key value in the coupled phenomena 531 represented by the numerical model. When the temperatures decreases below $-2.72{ }^{\circ} \mathrm{C}$, the 532 sorbet thermal properties as well as its consistency coefficient experience a sharp increase 533 (see Figure 4); as a consequence, both the fluid flow and the heat transfer are significantly 534 affected, promoting a major decrease in the gradient of axial temperature near the dasher 535 (see Figure 9). 
536 Two sensitivity tests were conducted in order to evaluate the influence of key parameters 537 on model predictions.

538 In building the numerical model, we have assumed a typical value for the thermal 539 conductivity of the solid elements which were taken into account (dasher and blades). One 540 may ask the importance of heat conduction in these solid elements on the predicted 541 temperature. Figure 9A presents the results of a first sensitivity test: black and grey lines 542 correspond to the temperature profiles after setting the thermal conductivity of solids to 15 $543 \mathrm{~W} \cdot \mathrm{m}^{-1} \cdot \mathrm{K}^{-1}$ and to zero, respectively. The thermal conductivity of solids is many times 544 greater than that for non-aerated sorbet (see Figure 4D); solid elements contribute to reduce 545 temperature gradients within the SSHE. With no conduction in solids, the predicted 546 temperature profile along the SSHE axis becomes slightly colder, from $0.1{ }^{\circ} \mathrm{C}$ at the 547 exchanger inlet $(z=0)$ up to about $0.35^{\circ} \mathrm{C}$ at its outlet $(z=0.4 \mathrm{~m})$; the latter difference can 548 be found also between the corresponding surface-averaged temperatures at the exit of the 549 outlet pipe (squares in Figure 9A). We can conclude that the influence of conduction in 550 solids on the predicted temperature along the SSHE axis is relatively weak, because it 551 exhibits the same order of magnitude than the difference between temperature 552 measurements and predictions.

553 Figure 9B summarizes the results of a second sensitivity test with the numerical model, in 554 order to assess the influence of the heat transfer coefficient assumed at the internal side of 555 the SSHE inner cylinder wall. The black line displays the temperature profile obtained after 556 setting this coefficient to $2500 \mathrm{~W} \cdot \mathrm{m}^{-2} \cdot \mathrm{K}^{-1}$; dark-grey and light-grey lines correspond to 557 results obtained after increasing and decreasing that value by $20 \%$, respectively. After 558 increasing the heat transfer coefficient, the liquid is exposed to more effective cooling 559 while travelling in the SSHE. As a consequence, the predicted temperature profile along the 
560 SSHE axis becomes relatively colder, from $-1.3{ }^{\circ} \mathrm{C}$ at the exchanger inlet to $-1.8{ }^{\circ} \mathrm{C}$ at its 561 outlet; hence, the initial freezing temperature is reached early (at about $z=0.025 \mathrm{~m}$, see 562 dark grey line in Figure 9B). Effects of opposite sign and smaller magnitude take place 563 after decreasing the heat transfer coefficient. Therefore, the value $2500 \mathrm{~W} \cdot \mathrm{m}^{-2} \cdot \mathrm{K}^{-1}$ proposed 564 by Arellano et al. (2013c) allows a reliable prediction of the product temperature.

566 The convective heat transfer resistance between the external side of the SSHE inner 567 cylinder and the refrigerant fluid $\left(1 / h_{\text {outside }}\right)$ cannot be neglected. Indeed, such an 568 assumption is equivalent to estimate $U=k_{w} / e_{w} \approx 7500 \mathrm{~W} \cdot \mathrm{m}^{-2} \cdot \mathrm{K}^{-1}$ in equation (8). As 569 demonstrated above, even for $U=3000 \mathrm{~W} \cdot \mathrm{m}^{-2} \cdot \mathrm{K}^{-1}$ the product temperature is largely 570 underestimated.

571 In this CFD approach the heat transfer between the internal side of the wall and the product

572 is directly calculated by the convection-conduction equation. Therefore no convective heat 573 transfer coefficient is required on this side of the SSHE inner cylinder. Nevertheless, the 574 order of magnitude of an hypothetical coefficient can be estimated from model predictions. 575 The averaged heat transfer coefficient between the liquid product and the internal side of 576 the SSHE inner cylinder could be defined by $h_{\text {inside }}=\frac{\dot{m}\left(\hat{H}_{\text {outlet }}-\hat{H}_{\text {inlet }}\right)}{A_{\text {wall }}\left(\bar{T}_{\text {wall }}-\bar{T}\right)}$

$578 \underline{\text { where }} \dot{m}$ is the product mass flow rate; $\hat{H}_{\text {inlet }}$ and $\hat{H}_{\text {outlet }}$ are specific enthalpy $(\mathrm{J} / \mathrm{kg})$ 579 values at the SSHE inlet and outlet respectively; $A_{\text {wall }}$ is heat exchange area, $\bar{T}_{\text {wall }}$ the averaged wall temperature, and $\underline{\bar{T}}$ an averaged product temperature. The difficulty to 
581 define and to calculate such a coefficient comes from that, towards the SSHE outlet, the 582 phase change of the product occurs under recirculation (see for instance Figure 7); the flow 583 pattern is very far from plug flow. Therefore the logarithmic mean temperature difference 584 between SSHE inlet and outlet cannot be applied. We choose to use the surface averaged 585 temperature at the internal side of the wall and the volume averaged temperature of the 586 product in the cylindrical part of the SSHE (say, excluding the inlet and outlet bowls). In 587 the case of reference operating conditions $\left(\dot{m}_{m i x}=50 \mathrm{~kg} / \mathrm{h}, T_{R}=-15.3^{\circ} \mathrm{C}\right.$ and $f_{\text {rot }}=750$ $588 \mathrm{rpm}$ ), we obtain $\bar{T}_{\text {wall }}=-3.49{ }^{\circ} \mathrm{C}$ and $\bar{T}=-3.43{ }^{\circ} \mathrm{C}$; the difference is very small, about

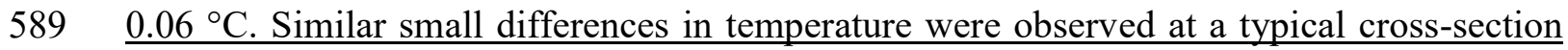
590 of the SSHE (Figure 8C, right display): the range of temperature is about $0.1{ }^{\circ} \mathrm{C}$. These 591 findings denote that either the radial mixing or the heat transfer between wall and product 592 are very efficient. Equation (16) provides an estimate for the "internal" heat transfer 593 coefficient (above $10^{5} \mathrm{~W} \cdot \mathrm{m}^{-2} \cdot \mathrm{K}^{-1}$ ) which appears too large compared to the "external" one 594 obtained from equation (8): $h_{\text {outside }}=\frac{1}{1 / U-e_{w} / k_{w}} \approx 3750 \mathrm{~W} \cdot \mathrm{m}^{-2} \cdot \mathrm{K}^{-1}$.

595 At this stage it is difficult to propose a general correlation for the inside heat transfer 596 coefficient, notably because only one product was considered. At least, products with 597 different initial freezing point and consistency should be tested and / or simulated.

\section{$599 \quad$ 5.3. Sensibility to mesh refinement}

600 The representation of the gradients of state variables in the numerical model (velocity, 601 pressure, temperature) is expected to become progressively finer as the mesh resolution 602 increases. Its influence on temperature predictions was evaluated by comparing results 
603 obtained with three meshes, constituted of increasing number of elements in the whole 604 computational domain $\left(6.5 \times 10^{5}, 1.5 \times 10^{6}\right.$ and $3.5 \times 10^{6}$ elements $)$. These meshes were built 605 as described above and then used for solving the problem under reference operating 606 conditions $\left(\dot{m}_{\text {mix }}=50 \mathrm{~kg} / \mathrm{h}, T_{R}=-15.3^{\circ} \mathrm{C}\right.$ and $\left.f_{\text {rot }}=750 \mathrm{rpm}\right)$.

607 Figure 10 compares Arellano et al. (2013a)'s measurements (indicated by circles) with the 608 temperature profiles in the SSHE as predicted by the numerical model after using these 609 three meshes. The three temperatures profiles behaved similarly in the central region of the 610 heat exchanger $(0.05<z<0.35 \mathrm{~m})$, with differences below $0.1{ }^{\circ} \mathrm{C}$ with respect to the 611 results achieved with the intermediate mesh $\left(1.5 \times 10^{6}\right.$ elements $)$. After increasing the mesh 612 resolution $\left(3.5 \times 10^{6}\right.$ elements $)$, the predicted temperature profile became slightly warmer 613 near the exchanger inlet $(\mathrm{z}<0.05 \mathrm{~m})$; as a consequence, the initial freezing temperature is 614 reached a few millimeters later than with the intermediate mesh. Effects of opposite sign 615 and similar magnitude take place after decreasing the mesh resolution $\left(6.5 \times 10^{5}\right.$ elements $)$.

616 Weaker effects can be observed, in both cases, near the exchanger outlet $(z>0.35 \mathrm{~m})$. The 617 whole set of temperature predictions is coherent with Arellano et al. (2013a)'s 618 measurements.

\subsection{Effect of rotation frequency}

621 The influence of the dasher rotation frequency was assessed by employing the numerical model and comparing its predictions with the observations reported by Arellano et al.

623 (2013a) at 545, 750 and $1000 \mathrm{rpm}$. The results on the line through the temperature sensors 624 are presented in Figure 11. The simulated values are in quite good agreement with the 625 experimental data. 
626 It is noteworthy that inside the exchanger the experimental data were already quite similar

627 for all frequencies, and as well, the simulated values presented the same behavior. This 628 could be due to two opposing effects: on one hand, an increase on the rotation frequency 629 increases the heat transfer which tends to decrease fluid temperature; on the other hand, an 630 increase in the rotation frequency increases the viscous dissipation in the fluid leading to 631 higher temperatures.

\subsection{Effect of refrigerant temperature}

634 The influence of the refrigerant temperature on the profiles following the sensors can be 635 appreciated in Figure 12. The profiles for the curves at $T_{R} \geq-15.3{ }^{\circ} \mathrm{C}$ show a good agreement with the experimental values while the profile for $T_{R}=-20.1{ }^{\circ} \mathrm{C}$ did not.

637 However, the general trend of the profile is preserved; a sharp decrease in temperature is observed near the entrance of the SSHE until the initial freezing temperature of the sorbet mix, followed by a slow decrease for most of the exchanger and a small decrease near the exit of the SSHE (at about $z=0.36 \mathrm{~m}$ ) due to the exit recirculation. Logically, the point at

641 which the initial freezing temperature is reached is closer to the entrance for lower refrigerant temperature.

643 The lack of agreement at $T_{R}=-20.1{ }^{\circ} \mathrm{C}$ could be explained by the fact that for low 644 refrigerant temperatures, the wall temperature along the SSHE could reach values lower 645 than $-6^{\circ} \mathrm{C}$. As presented in Figure 4B, experimental values for sorbet consistency index 646 are only available until this temperature. For temperatures below this point, the consistency 647 index was extrapolated linearly in this work; however, lower temperatures in the mix would 648 mean higher ice contents that strongly modify the apparent rheological properties of sorbet 
649 (i.e. increasing the consistency index exponentially rather than linearly). This lack of 650 extrapolation capacity could lead to miscalculations of the velocity profile in the exchanger 651 and a strong under-prediction of the viscous dissipation effect in the simulations that, even 652 if only located at the exit of the SSHE, could influence the results all over the exchanger 653 due to the back-mixing observed.

\subsection{Effect of mix flow rate}

656 The influence of the mix flow rate was analyzed through simulations carried out at the 657 conditions that were adopted by Arellano et al. (2013a): $\dot{m}_{m i x}=25,50$ and $75 \mathrm{~kg} / \mathrm{h}$. 658 Results over the line that follows the position of the temperature sensors are shown in 659 Figure 13. The profiles calculated at $\dot{m}_{m i x} \geq 50 \mathrm{~kg} / \mathrm{h}$ are in good agreement with the 660 experimental data while the profile at $\dot{m}_{m i x}=25 \mathrm{~kg} / \mathrm{h}$ shows a good agreement until $z=0.2$ $661 \mathrm{~m}$ after which a strong decrease in temperature is observed. This could be explained since 662 lower mix flow rates leads to an increase in the residence time within the exchanger, which 663 in turn leads to fluid temperatures reaching values closer to the refrigerant temperature (the 664 outlet temperature calculated value for this simulation was $\left.-11.1^{\circ} \mathrm{C}\right)$. As explained before, 665 there is an uncertainty on the rheological behavior of the sorbet under such conditions; that 666 could affect the prediction of velocity profiles and lead to underestimate the viscous 667 dissipation effect in the exchanger.

\section{Conclusion and perspectives}

670 The production of non-aerated sorbet inside a scraped surface heat exchanger was studied 671 with the help of a 3D numerical model able to solve the coupled problem of fluid flow, heat 
672 transfer and product transformation. Fluid flow is very complex in the volume confined by

673 the dasher, the blades and the wall of the SSHE inner cylinder. Fluid flow drives thermal 674 convection which determines ice fraction and finally rheology evolution along the SSHE. 675 Rheology, in turn, influences fluid flow. Model predictions compared favorably with 676 available measurements when temperature remains in the range for which the sorbet 677 rheology was available, indicating the global consistency of the modeling approach.

678 Sensitivity tests allowed us to assess the influence of key model parameters. On one hand, 679 the influence of the heat transfer coefficient at the exchanger wall is relatively high; after 680 increasing that coefficient by $20 \%$, the predicted temperatures near the SSHE outlet 681 decreased by about $1.8^{\circ} \mathrm{C}$. Such an increase of the heat transfer coefficient could be 682 achieved by intensifying the heat exchange between the evaporating refrigerant and the heat 683 exchanger cylinder. In the scope of future experimental campaigns with the pilot unit here 684 considered, we strongly recommend the inclusion of temperature monitoring at the inner 685 wall of the SSHE as a necessary step for a finer estimation of that coefficient. On the other 686 hand, the influence of conduction in solids (dasher, blades) is relatively weak: outlet 687 temperatures decreased by $0.35{ }^{\circ} \mathrm{C}$ when conduction in solids was ignored. Reducing the 688 conduction, by using a hollow dasher for example, is therefore expected to slightly improve 689 the SSHE performance.

690 Post-processing of model predictions helped us to extend the understanding of phenomena 691 under consideration. For instance, the occurrence of recirculation near the blades endings 692 allows backflow from the outlet region. This backflow brings cold, high ice-content, fluid 693 near to the inlet. This explains why temperatures between the blades and the dasher in the 694 inlet region are much lower than the value prescribed at the SSHE entrance $\left(5^{\circ} \mathrm{C}\right.$, see for 695 instance Figure 9). This aspect would not be predicted with a 1D model assuming plug- 
696 flow and an overall uniform heat transfer coefficient. The temperature field summarizes the

697 strong coupling that occurs between the phenomena in the SSHE: on one hand, when the 698 temperature decreases below the initial freezing value $-2.72{ }^{\circ} \mathrm{C}$, sharp changes affects the 699 product properties, including its rheology; on the other hand, in addition to rotation and 700 mean axial flow, the product rheology drives the fluid motion and hence the convective 701 flux of heat. We argue that only the fully-coupled solution of this challenging problem can 702 provide realistic predictions.

703 In further work, on the base on the modeling of velocity and temperature fields, CFD will 704 be used to predict ice crystals growth and bubble fragmentation. For ice crystal growth, 705 backflow will be also crucial because it seeds the inlet region with ice crystals, hence 706 avoiding super-cooling. Bubble fragmentation in aerated sorbet mainly depends on shear 707 rate, elongation rate and apparent viscosity of the surrounding fluid, which can be provided 708 by the present work. Nevertheless, it should be kept in mind that experimental rheology 709 data should be completed for high shear rate and ice content, because it could affect bubble 710 fragmentation prediction. This way, 3D modeling of the coupled relevant phenomena could 711 be really helpful for industrial applications.

712 Looking forward, we focus our final words on the necessity of a broader experimental 713 dataset than the one available to the present study. Firstly, pressure drop measurements 714 should be included, as a way to validate the model predictions of complex fluid flow 715 occurring under heat transfer and product transformation in the SSHE. Secondly, other 716 operating conditions and product properties should be considered, for instance the initial 717 freezing point. Beyond the opportunity for complementary assessment of model 718 predictions, the availability of a broad dataset is necessary to identify heat transfer 
719 correlations in SSHE during crystallization. Recent efforts have been devoted on this

720 difficult subject (e.g. Saraceno et al., 2011; Rainieri et al., 2014). Lastly, the product

721 rheology must be fully characterized, as a way to improve the reliability of model

722 predictions under particular operating conditions (low refrigerant fluid temperature, low

723 mass flow rate). Such an enhanced characterization should include higher shear rates and

724 ice contents.

725

726 Acknowledgements

727 O.D.H.P. acknowledges the Administrative Department of Science and Technology of the 728 Republic of Colombia (COLCIENCIAS) for financial support through the program 729 "Generación del Bicentenario, 2012" during the development of this work.

730

731 


\section{References}

733 Abichandani, H., Sarma, S.C., \& Heldman, D. R. (1986). Hydrodynamics and heat transfer 734 in liquid full scraped surface heat exchangers - A review. Journal of Food Process 735 Engineering, 9, 121-141.

736 Arellano, M., Benkhelifa, H., Alvarez, G., \& Flick, D. (2013a). Experimental study and 737 modelling of the residence time distribution in a scraped surface heat exchanger during 738 sorbet freezing. Journal of Food Engineering, 117, 14-25.

739 Arellano, M., Flick, D., Benkhelifa, H., \& Alvarez, G. (2013b). Rheological 740 characterisation of sorbet using pipe rheometry during the freezing process. Journal of 741 Food Engineering, 119, 385-394.

742 Arellano, M., Benkhelifa, H., Alvarez, G., \& Flick, D. (2013c). Coupling population 743 balance and residence time distribution for the ice crystallization modeling in a scraped 744 surface heat exchanger. Chemical Engineering Science, 102, 502-513.

745 Baccar, M. \& Abid, M. S. (1997). Numerical analysis of three-dimensional flow and 746 thermal behaviour in a scraped-surface heat exchanger. Revue Générale de Thermique, 36, $747 \quad 782-790$.

748 Baccar, M. \& Abid, M. S. (1999). Simulation numérique des comportements hydro749 dynamiques et thermiques des échangeurs racleurs opérant en régime turbulent. $750 \quad$ International Journal of Thermal Sciences, 38, 634-644. 
751 Błasiak, P. \& Pietrowicz, S. (2016). Towards a better understanding of 2D thermal-flow 752 processes in a scraped surface heat exchanger. International Journal of Heat and Mass 753 Transfer, 98, 240-256.

754 Boccardi, G., Celata, G.P., Lazzarini, R., Saraceno, L., \& Trinchieri, R. (2010). 755 Development of a heat transfer correlation for a scraped-surface heat exchanger. Applied 756 Thermal Engineering, 30, 1101-1106.

757 Bongers, P. M. M. (2006). A heat transfer model of a scraped surface heat exchanger for 758 ice cream. Computer Aided Chemical Engineering, 21, 539-544.

759 Casenave, C., Dochain, D., Alvarez, G., Arellano, M., Benkhelifa, H., \& Leducq, D. 760 (2013). Control of a nonlinear ice cream crystallization process. IFAC Proceedings 761 Volumes, 46, 717-722.

762 Casenave, C., Dochain, D., Alvarez, G., Arellano, M., Benkhelifa, H., \& Leducq, D. 763 (2014). Model identification and reduction for the control of an ice cream crystallization 764 process. Chemical Engineering Science, 119, 274-287.

765 Choi, Y. \& Okos, M. R. (1986). Effects of temperature and composition on the thermal 766 properties of foods. In: Le Maguer, M. (Ed.), Food Engineering and Process Applications, 767 Volume 1: Transport Phenomena, London, Elsevier, pp. 93-101.

768 Cogné, C., Andrieu, J., Laurent, P., Besson, A., \& Nocquet, J. (2003) Experimental data 769 and modelling of thermal properties of ice creams. Journal of Food Engineering, 58, 331770341. 
771 Cook, K. L. K. \& Hartel, R. W. (2010) Mechanisms of ice crystallization in ice cream

772 production. Comprehensive Reviews in Food Science and Food Safety, 9, 213-222.

773 Crespi-Llorens, D., Vicente, P., Viedma, A. (2016). Flow pattern of non-Newtonian fluids 774 in reciprocating scraped surface heat exchangers. Experimental Thermal and Fluid Science, $77576,306-323$.

776 D'Addio, L., Carotenuto, C., DiNatale, F., \& Nigro, R. (2013). Heating and cooling of 777 hazelnut paste in alternate blades scraped surface heat exchangers. Journal of Food 778 Engineering, 115, 182-189.

779 Dehkordi, K. S., Fazilati, M. A., \& Hajatzadeh, A. (2015). Surface scraped heat exchanger 780 for cooling Newtonian fluids and enhancing its heat transfer characteristics, a review and a 781 numerical approach. Applied Thermal Engineering, 87, 56-65.

782 Dorneanu, B., Bildea, C. S., Grievink, J., \& Bongers, P. M. M. (2009). A first-principles 783 model for the freezing step in ice cream manufacture. Computer Aided Chemical 784 Engineering, 26, 171-176.

785 Duffy, B. R., Wilson, S. K., Lee, M. E. M. (2007). A mathematical model of fluid flow in a 786 scraped-surface heat exchanger. Journal of Engineering Mathematics, 57, 381-405.

787 Dumont, E., Fayolle, F., \& Legrand, J. (2000a). Electrodiffusional wall shear rate analysis 788 in scraped surface heat exchanger. AIChE Journal, 46, 1138-1148.

789 Dumont, E., Fayolle, F., \& Legrand, J. (2000b). Flow regimes and wall shear rates 790 determination within a scraped surface heat exchanger. Journal of Food Engineering, 45, $791 \quad 195-207$. 
792 Goff, H. D. \& Hartel, R. W. (2013). Ice Cream. Boston, Springer.

793 González-Ramírez, J. E. (2012). Contribution au contrôle par la modélisation d'un procédé 794 de cristallisation en continu. Ph.D. Thesis, AgroParisTech, Paris.

795 González-Ramírez, J. E., Leducq, D., Arellano, M., \& Alvarez, G. (2013a). Energy 796 consumption optimization of a continuous ice cream process. Energy Conversion and 797 Management, 70, 230-238.

798 González-Ramírez, J. E., Leducq, D., Arellano, M., \& Alvarez, G. (2013b). Model of a 799 continuous crystallization process for a sorbet by the moments methodology. Revista 800 Internacional de Métodos Numéricos para Cálculo y Diseño en Ingeniería, 29, 215-224.

801 Härröd, M. (1986). Scraped surface heat exchangers: A literature survey of flow patterns, 802 mixing effects, residence time distribution, heat transfer and power requirements. Journal 803 of Food Process Engineering, 9, 1-62.

804 Lakhdar, M. B., Cerecero, R., Alvarez, G., Guilpart, J., Flick, D., \& Lallemand, A. (2005). 805 Heat transfer with freezing in a scraped surface heat exchanger. Applied Thermal 806 Engineering, 25, 45-60.

807 Lian, G., Moore, S., \& Heeney, L. (2006). Population balance and computational fluid 808 dynamics modelling of ice crystallisation in a scraped surface freezer. Chemical 809 Engineering Science, 61, 7819-7826.

810 Martínez, D. S., Solano, J. P., Illan, F., \& Viedma, A. (2014). Analysis of heat transfer 811 phenomena during ice slurry production in scraped surface plate heat exchangers. 812 International Journal of Refrigeration, 48, 221-232. 
813 Reiser, P., Birch, G. G., \& Mathlouthi, M. (2012). Physical properties. In: Mathlouthi, M.,

814 \& Reiser, P. (Eds.), Sucrose: Properties and Applications, Springer-Science, pp. 186-223.

815 Qin, F. G. F., Chen, X. D., \& Russell, A. B. (2003). Heat transfer at the subcooled-scraped 816 surface with/without phase change. AIChE Journal, 49, 1947-1955.

817 Qin, F. G. F., Chen, X. D., Ramachandra, S., \& Free, K. (2006). Heat transfer and power 818 consumption in a scraped-surface heat exchanger while freezing aqueous solutions. 819 Separation and Purification Technology, 48, 150-158.

820 Rainieri, S., Bozzoli, F., Cattani, L., \& Vocale, P. (2014). Parameter estimation applied to 821 the heat transfer characterisation of scraped surface heat exchangers for food applications. 822 Journal of Food Engineering, 125, 147-156.

823 Rao, C. S. \& Hartel, R. W. (2006). Scraped surface heat exchangers. Critical Reviews in 824 Food Science and Nutrition, 46, 207-219.

825 Saraceno, L., Boccardi, G., Celata, G. P., Lazzarini, R., \& Tinchieri, R. (2011). 826 Development of two heat transfer correlations for a scraped surface heat exchanger in an 827 ice-cream machine. Applied Thermal Engineering, 31, 4106-4112.

828 Skelland, A. H. P. (1958). Correlation of scraped-film heat transfer in the votator. Chemical 829 Engineering Science, 7, 166-175.

830 Stranzinger, M., Feigl, K., \& Windhab, E. (2001). Non-Newtonian flow behaviour in 831 narrow annular gap reactors. Chemical Engineering Science, 56, 3347-3363. 
832 Schenk, O., \& Gartner, K. (2004). Solving unsymmetric sparse systems of linear equations 833 with PARDISO. Future Generation Computer Systems, 20, 475-487.

834 Trommelen, A. M., Beek, W. J., \& Van De Westelaken, H. C. (1971). A mechanism for 835 heat transfer in a Votator-type scraped-surface heat exchanger. Chemical Engineering 836 Science, 26, 1987-2001.

837 Wang, W., Walton, J. H., \& McCarthy, K. L. (1999). Flow profiles of power law fluids in 838 scraped surface heat exchanger geometry using MRI. Journal of Food Process 839 Engineering, 22, 11-27.

840 Wang, W., Walton, J. H., \& McCarthy, K. L. (2000). Mixing in scraped surface heat 841 exchanger geometry using MRI. Journal of Food Process Engineering, 23, 403-418.

842 Yataghene, M., Pruvost, J., Fayolle, F., \& Legrand, J. (2008). CFD analysis of the flow 843 pattern and local shear rate in a scraped surface heat exchanger. Chemical Engineering and 844 Processing: Process Intensification, 47, 1550-1561.

845 Yataghene, M., Fayolle, F., \& Legrand, J. (2009). Experimental and numerical analysis of 846 heat transfer including viscous dissipation in a scraped surface heat exchanger. Chemical 847 Engineering and Processing: Process Intensification, 48, 1447-1458.

848 Yataghene, M., Fayolle, F., \& Legrand, J. (2011). Flow patterns analysis using 849 experimental PIV technique inside scraped surface heat exchanger in continuous flow 850 condition. Applied Thermal Engineering, 31, 2855-2868.

851 Yataghene, M., \& Legrand, J. (2013). A 3D-CFD model thermal analysis within a scraped 852 surface heat exchanger. Computers \& Fluids, 71, 380-399. 
853 Zimmerman, W. B. J. (2006). Multiphysics Modelling with Finite Element Methods. World 854 Scientific, Singapore. 


\section{FIGURE 1A)}

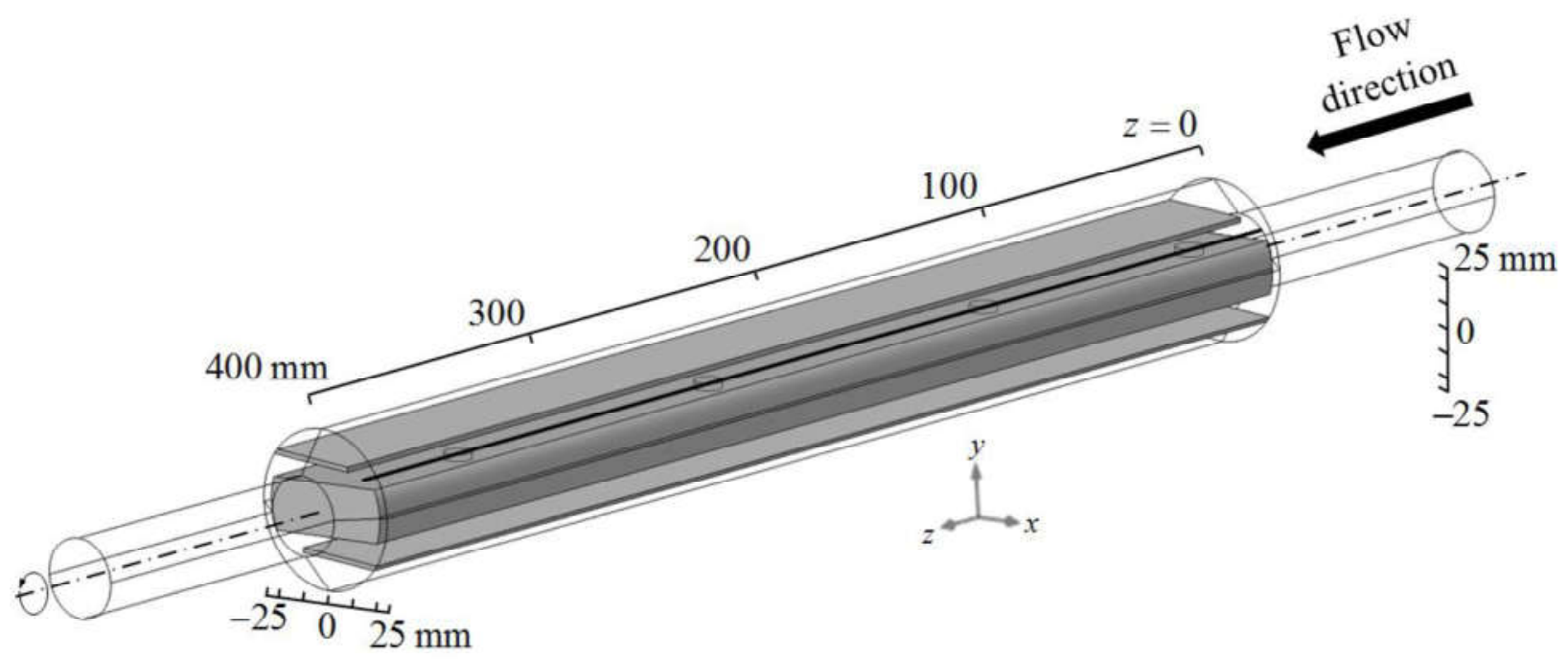




\section{FIGURE 1B)}

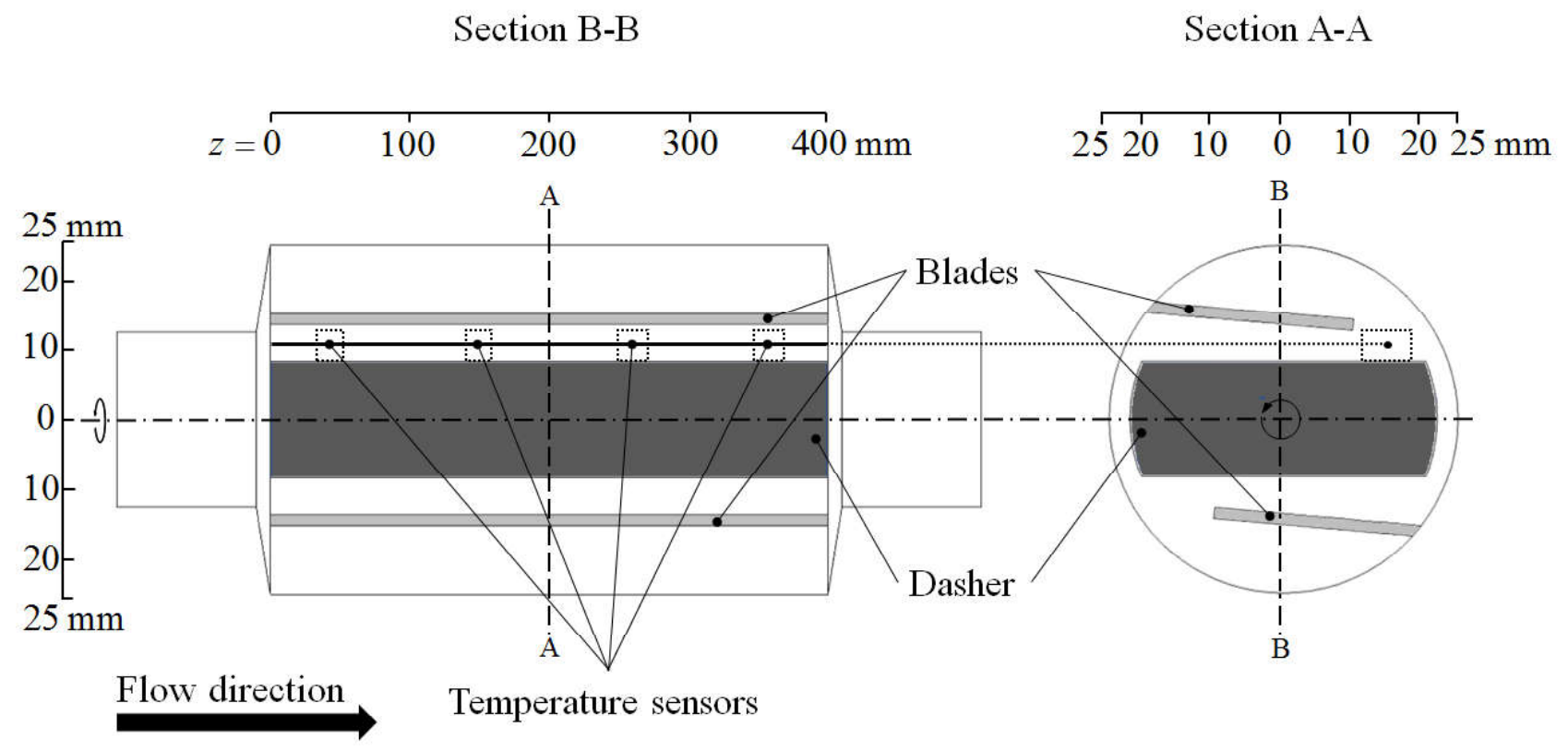

Figure 1. Schematic view of the SSHE pilot unit used for freezing lemon sorbet (Arellano et al., 2013a, 2013b, 2013c):
A) 3D view of the SSHE as represented in the numerical model, and
B) longitudinal (left) and cross-sectional (right) views of the SSHE as employed for displaying model predictions. 


\section{FIGURE 2)}

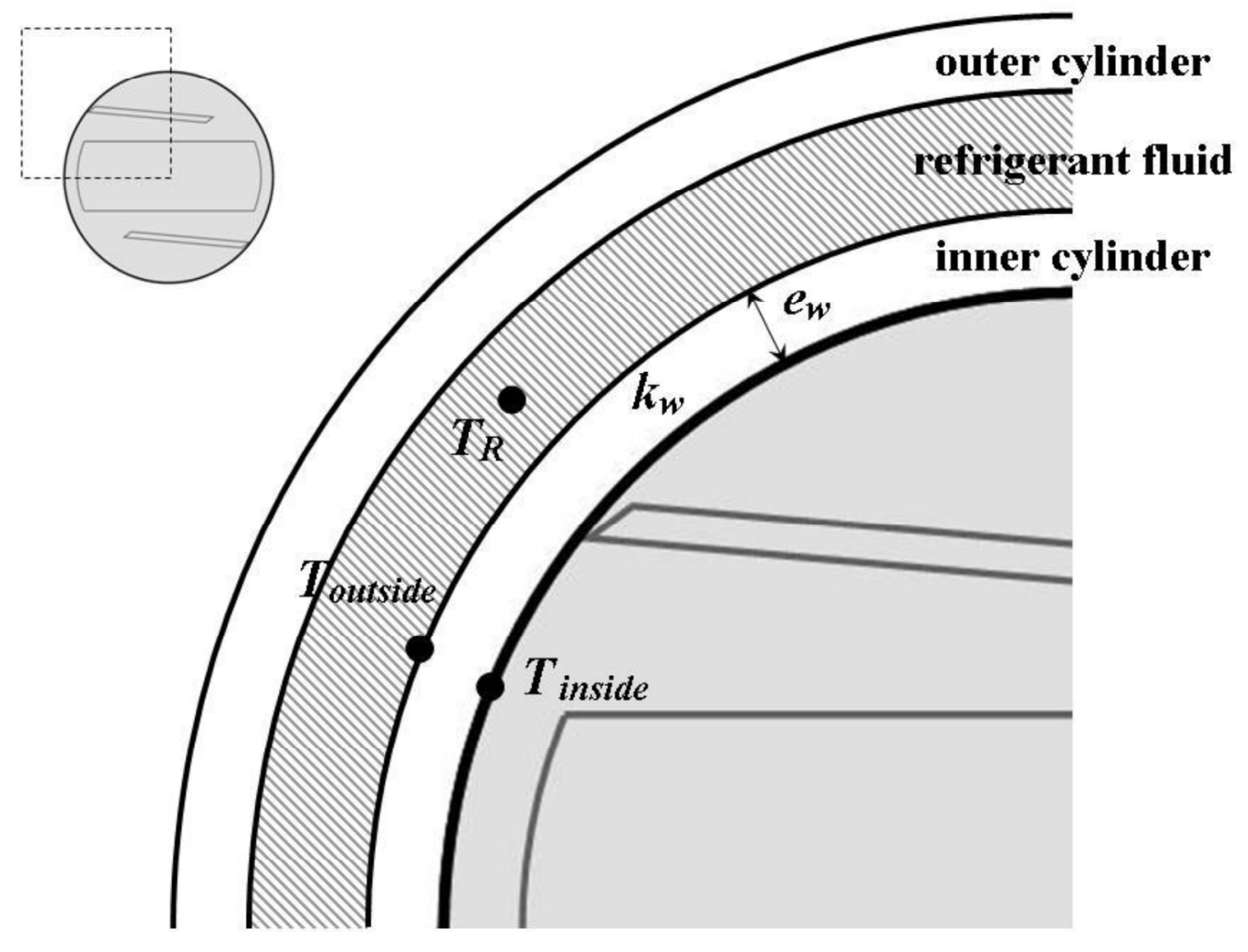

Figure 2. Cross-section view of the SSHE. The computation domain taken into account by the numerical model is pictured in gray (see the whole cross-section view at top-left). This domain is delimited by the thickest line, which corresponds to the internal wall of the $\underline{\text { SSHE inner cylinder. Other black lines delimitate the SSHE outer and inner cylinders. The }}$ wall of the inner cylinder is characterized by thickness $e_{w}$, thermal conductivity $k_{w}$, and $\underline{\text { the outside and inside temperatures ( }} T_{\text {outside }}$ and $T_{\text {nside }}$ respectively). The dashed zone corresponds to the refrigerant fluid, characterized by evaporating temperature $T_{R}$ : 


\section{FIGURE 3)}

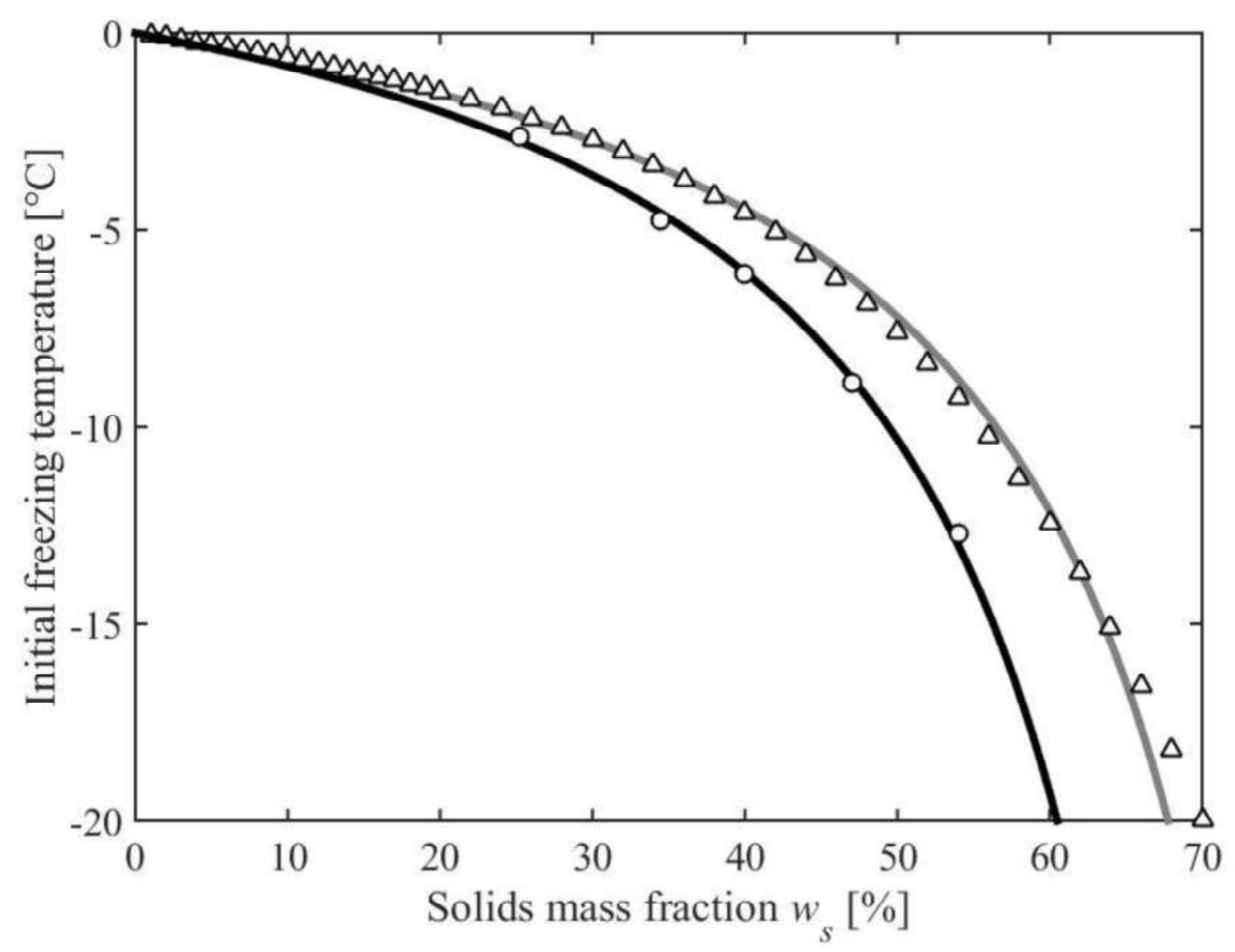

Figure 3. Freezing depression curve of concentrated lemon sorbet mix and sucrose solution:

(○) obtained experimentally for lemon sorbet mix by Gonzalez Ramirez (2012),

(一) estimated for lemon sorbet mix using equation (11),

$(\Delta)$ obtained experimentally for sucrose solutions by Reiser et al. (2012), and

(一) estimated for sucrose using equation (11). 
FIGURE 4A)

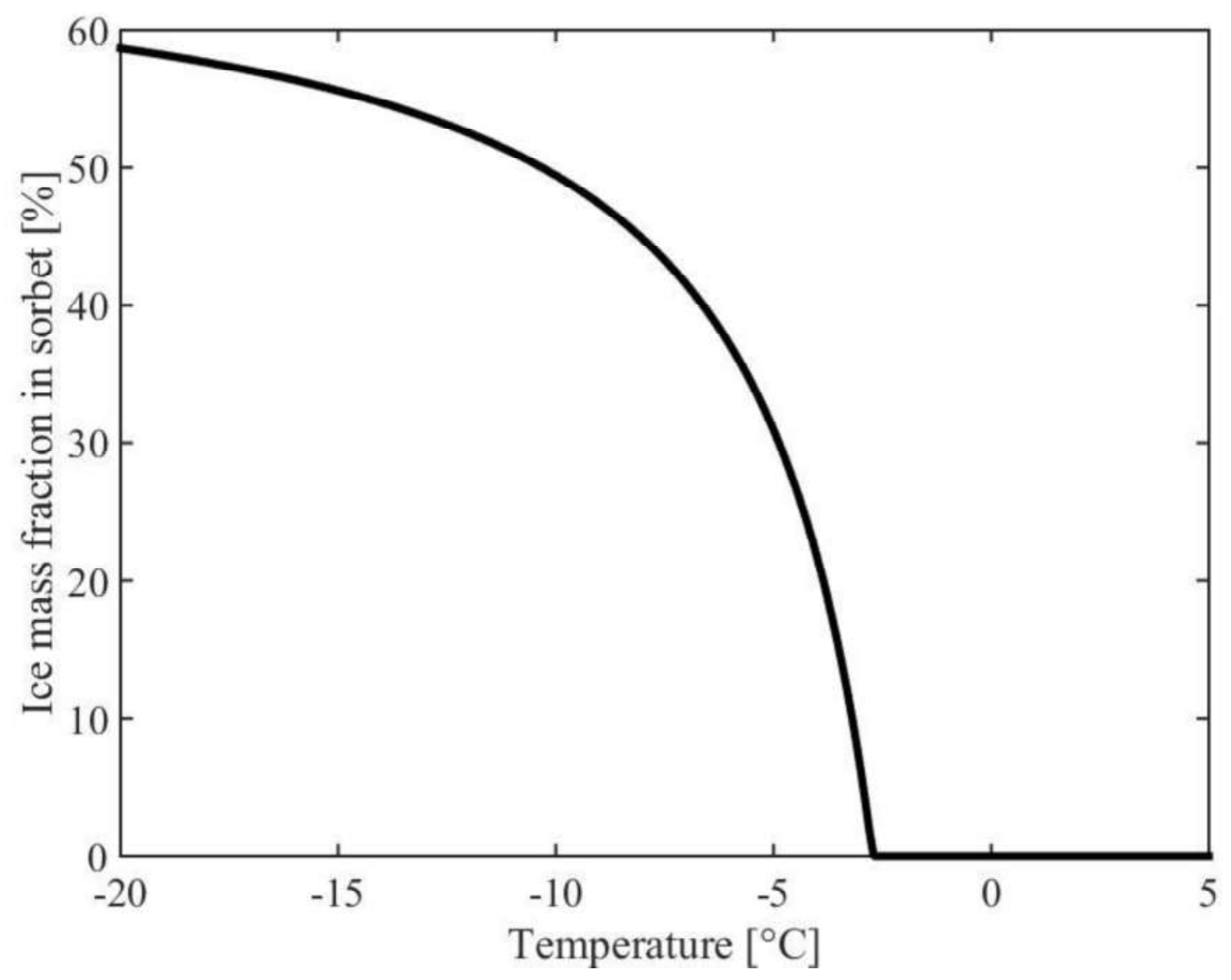


FIGURE 4B)

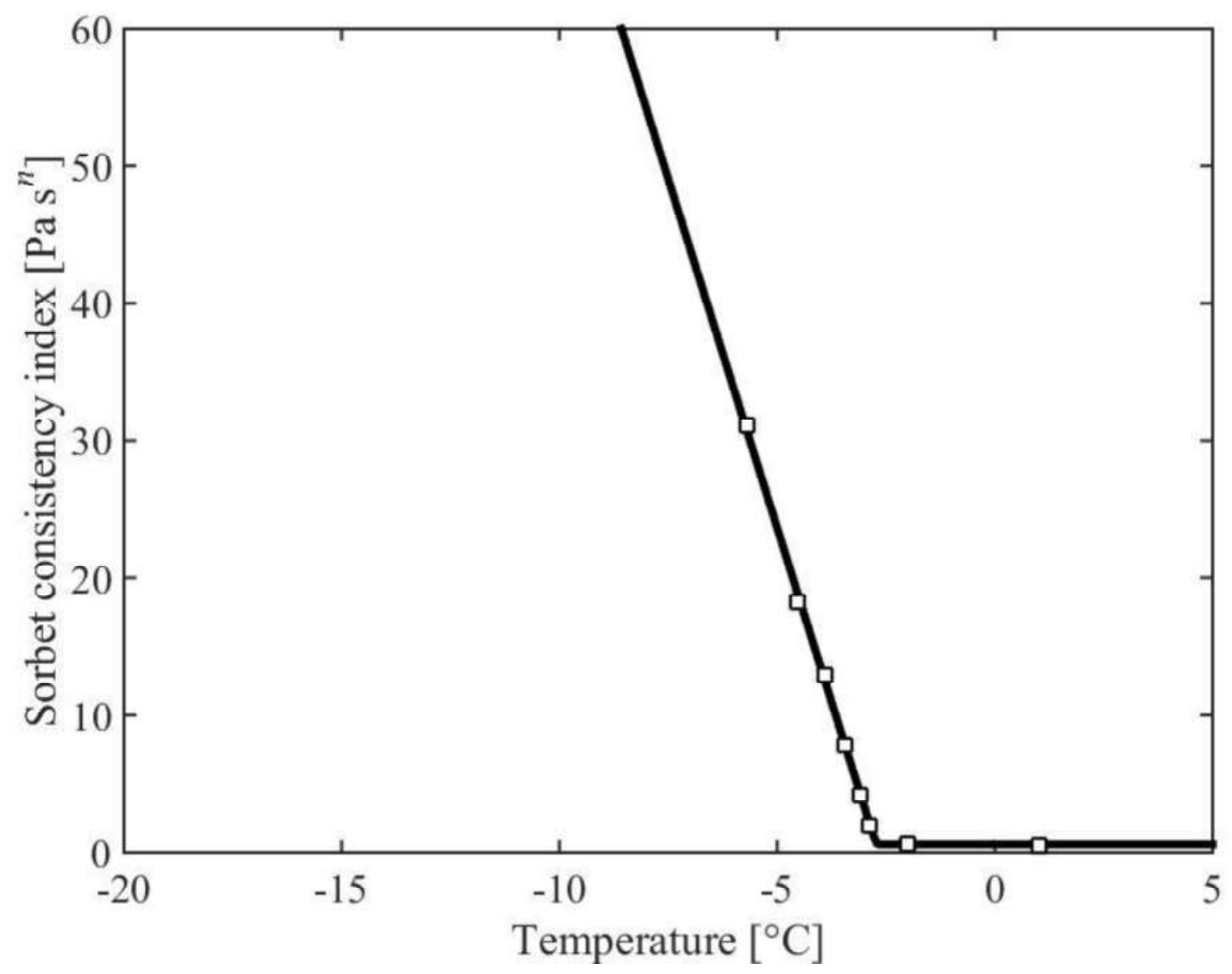


FIGURE 4C)

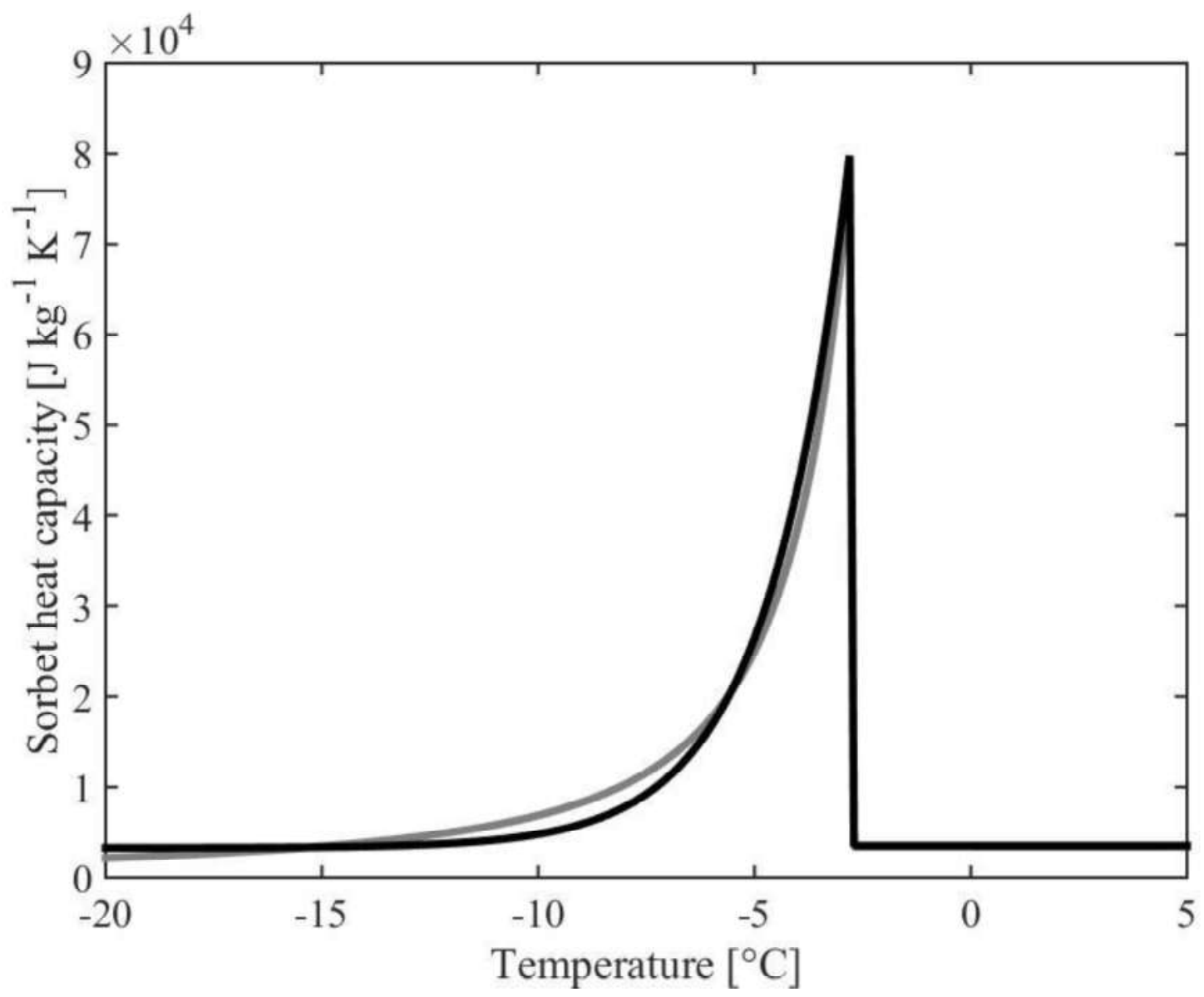




\section{FIGURE 4D)}

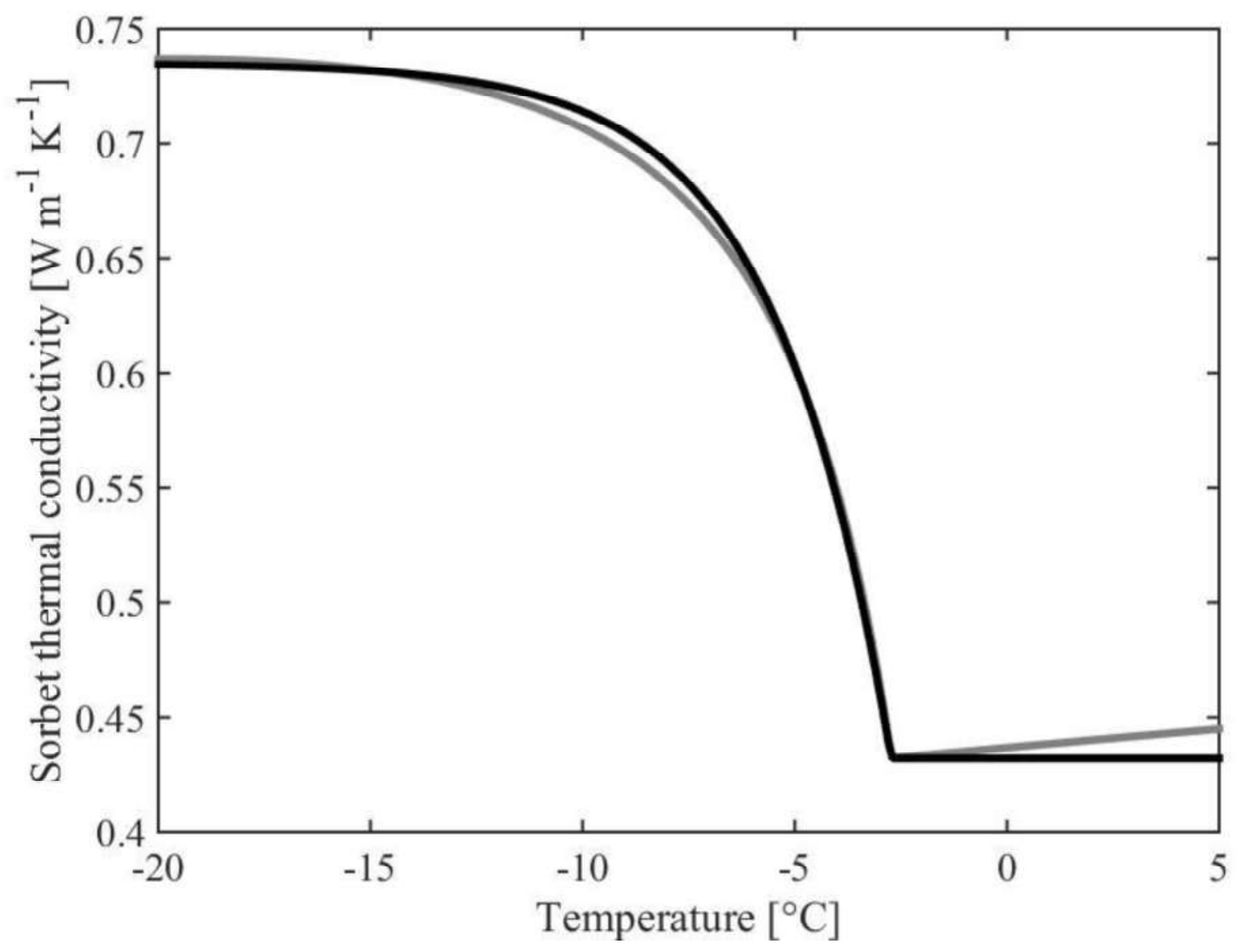

Figure 4. Sorbet physical properties as taken into account in this study:

A) ice mass fraction in sorbet according to temperature using equations (9-12);

B) consistency index:

( $\square$ ) obtained experimentally by Arellano et al. (2013b) and

(一) estimated using equation (13);

C) heat capacity:

(一) estimated as proposed by Cogné et al. (2003) and (-) estimated using equations (15);

D) thermal conductivity:

(一) estimated as proposed by Cogné et al. (2003) and (-) estimated using equations (16). 


\section{FIGURE 5A)}

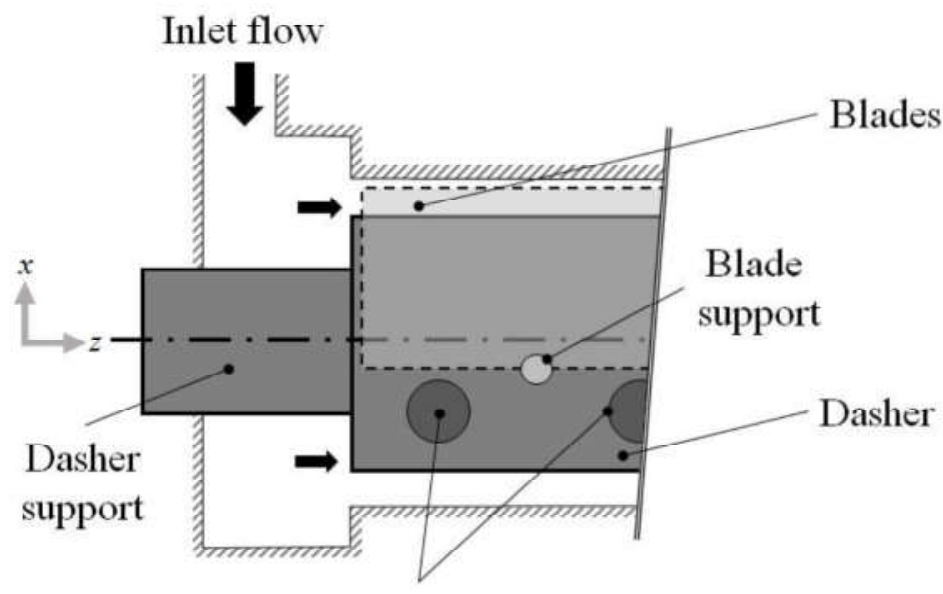

Temperature sensors

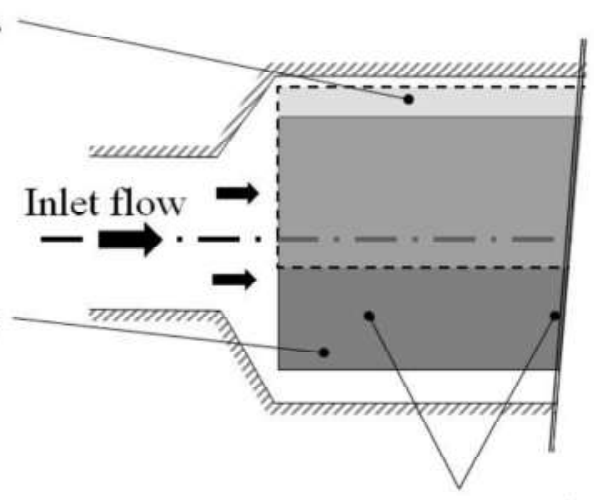

Temperature sensors location

\section{FIGURE 5B)}

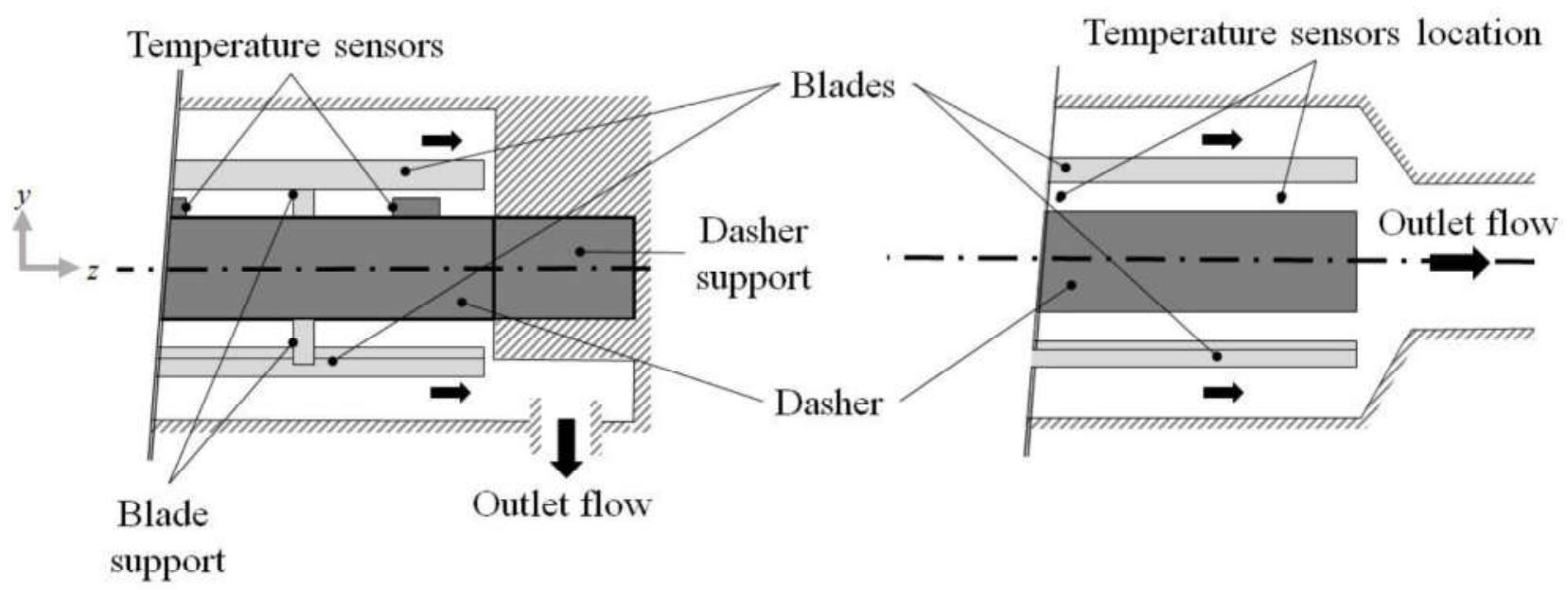

Figure 5. A) Actual cross-section view of the SSHE inlet bowl (left), and its representation in the numerical model (right). B) The same for the SSHE outlet bow. 


\section{FIGURE 6)}
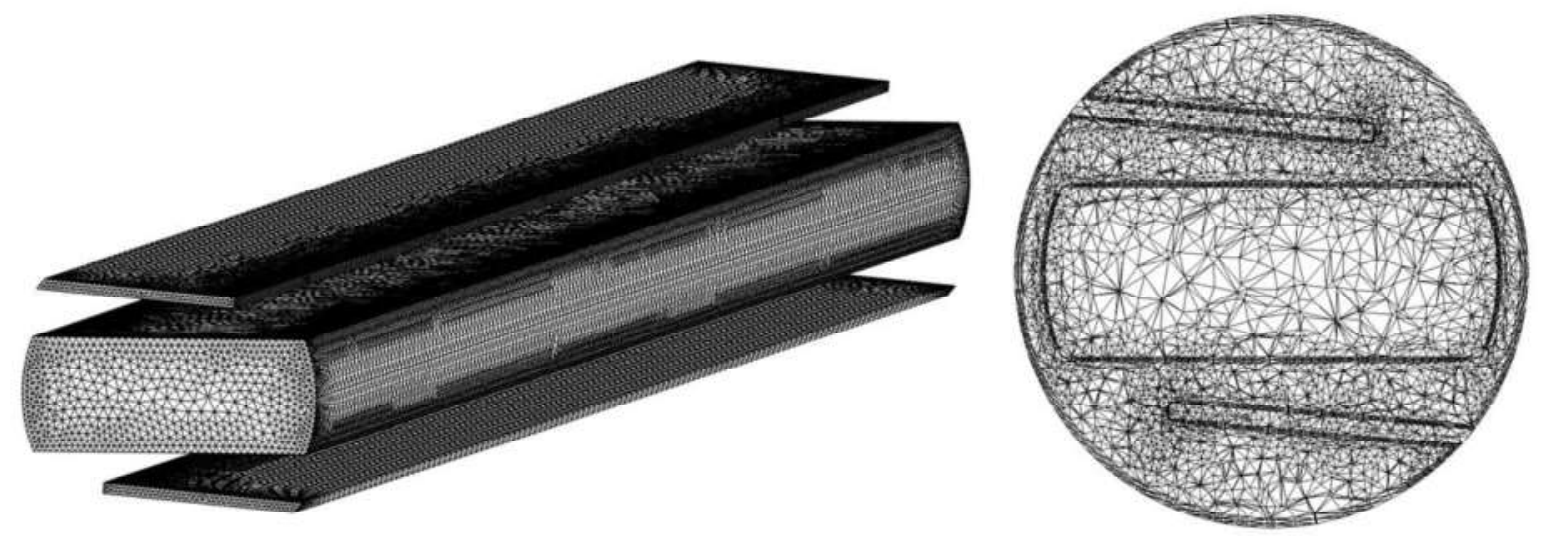

Figure 6. Mesh built for the simulations carried out in this work. Right: mesh around the solid elements (dasher and blades); left: cut view in the center of the SSHE inner cylinder. 


\section{FIGURE 7)}

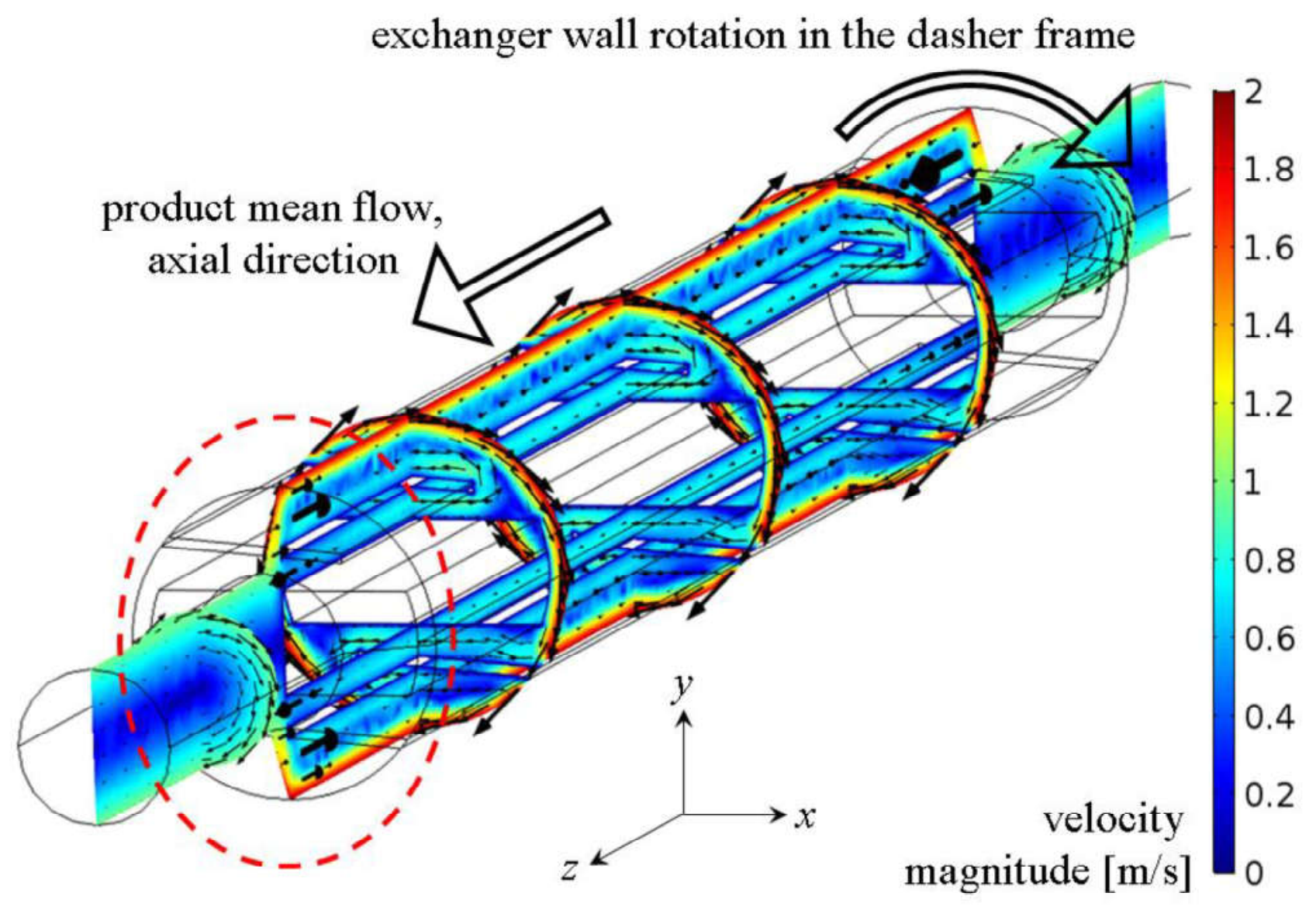

Figure 7. Velocity field in the SSHE, as predicted by the numerical model under reference operating conditions: $\dot{m}_{\text {mix }}=50 \mathrm{~kg} / \mathrm{h}, T_{R}=-15.3{ }^{\circ} \mathrm{C}$ and $f_{\text {rot }}=750 \mathrm{rpm}$. Velocity vectors presented in the plane $\mathrm{YZ}$ containing the axial direction are not in the same scale than those in the three planes XY crossing the axial direction. 


\section{FIG. 8A) Velocity magnitude [m/s]}
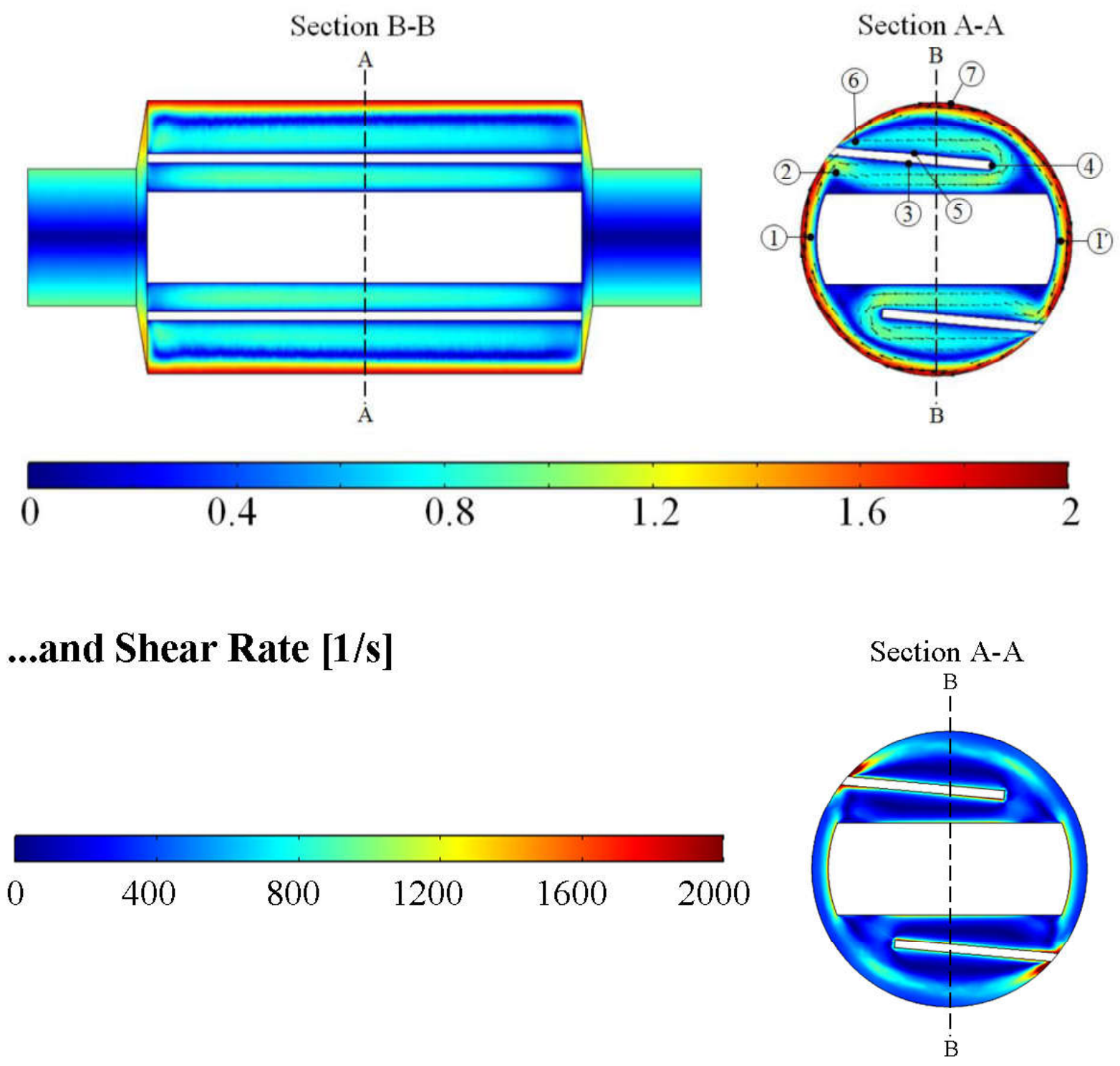


\section{FIGURE 8B) Pressure [Pa]}
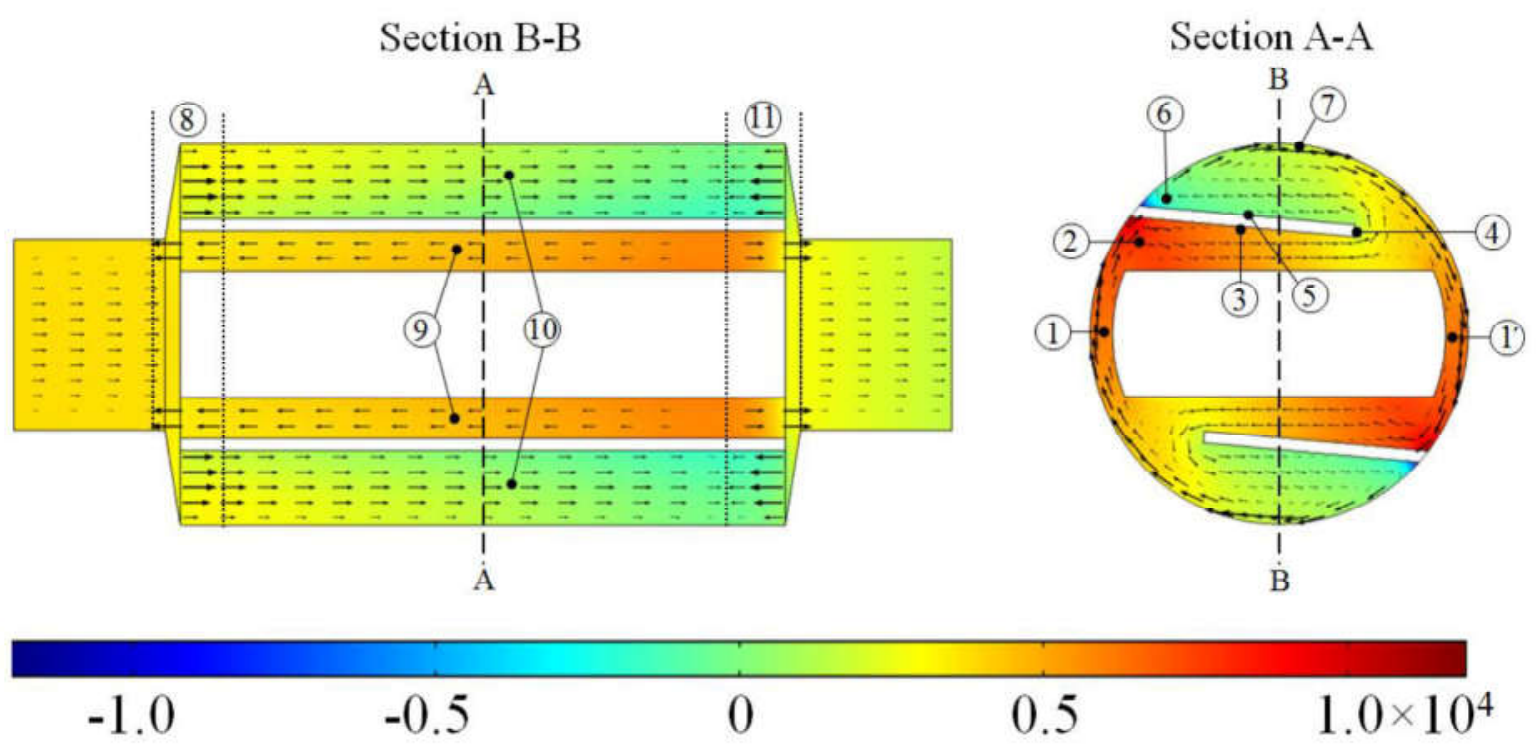

\section{FIGURE 8C) Temperature $\left[{ }^{\circ} \mathrm{C}\right]$}

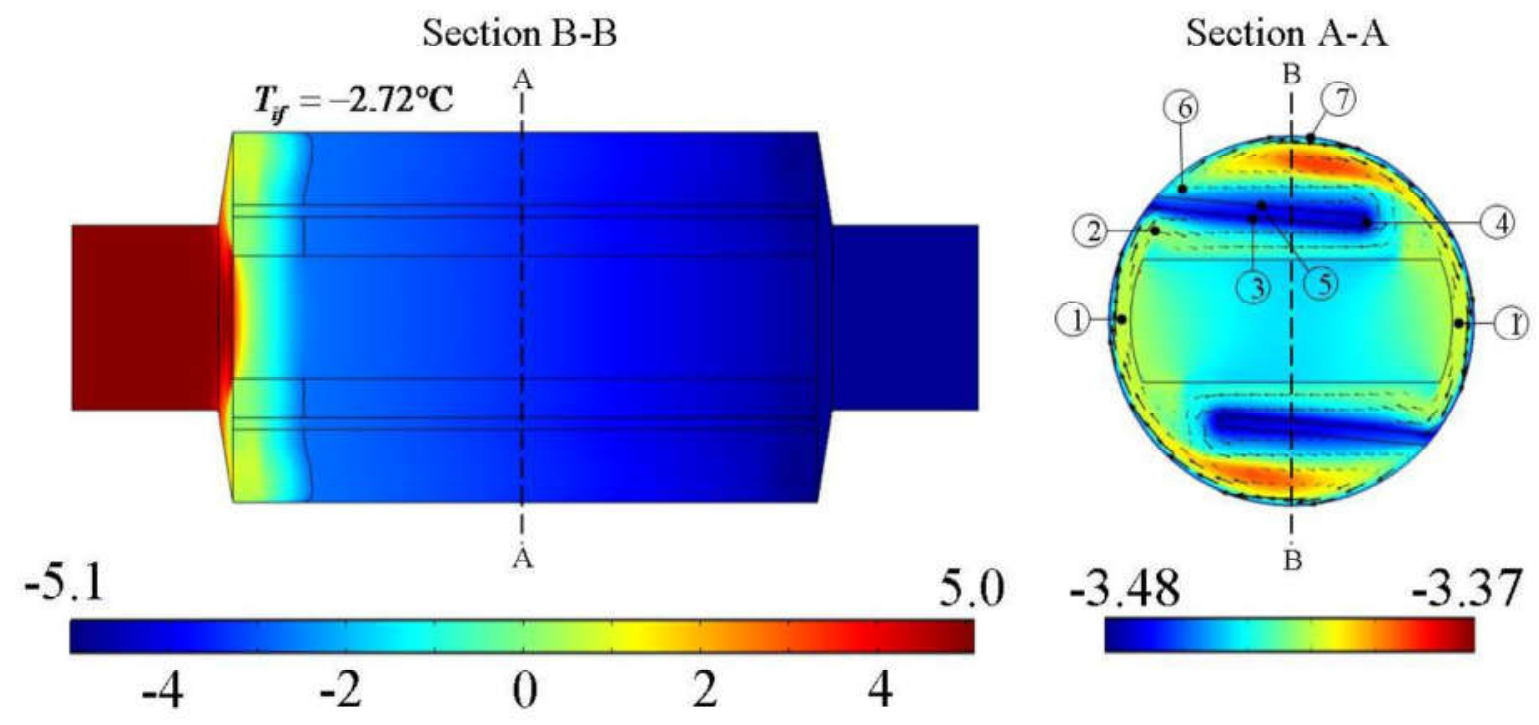


FIG. 8D) Specific enthalpy $[\mathrm{J} / \mathrm{kg}]$ and ice mass fraction
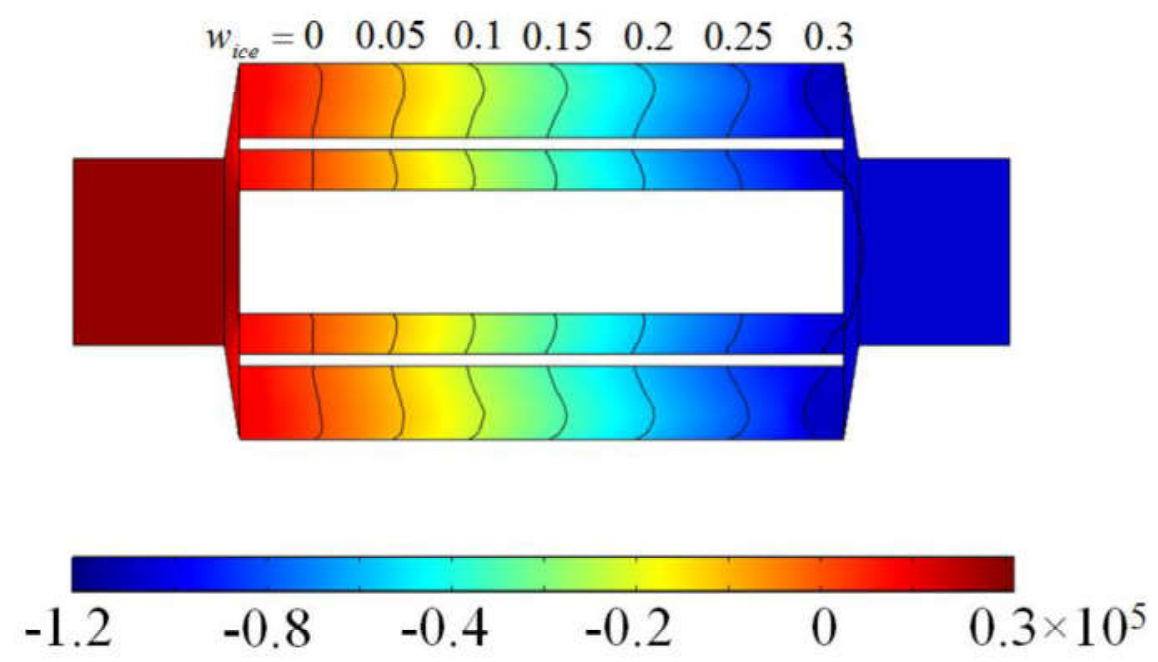


\section{FIGURE 8E) Viscous dissipation rate $\left[\mathrm{W} / \mathrm{m}^{3}\right]$}
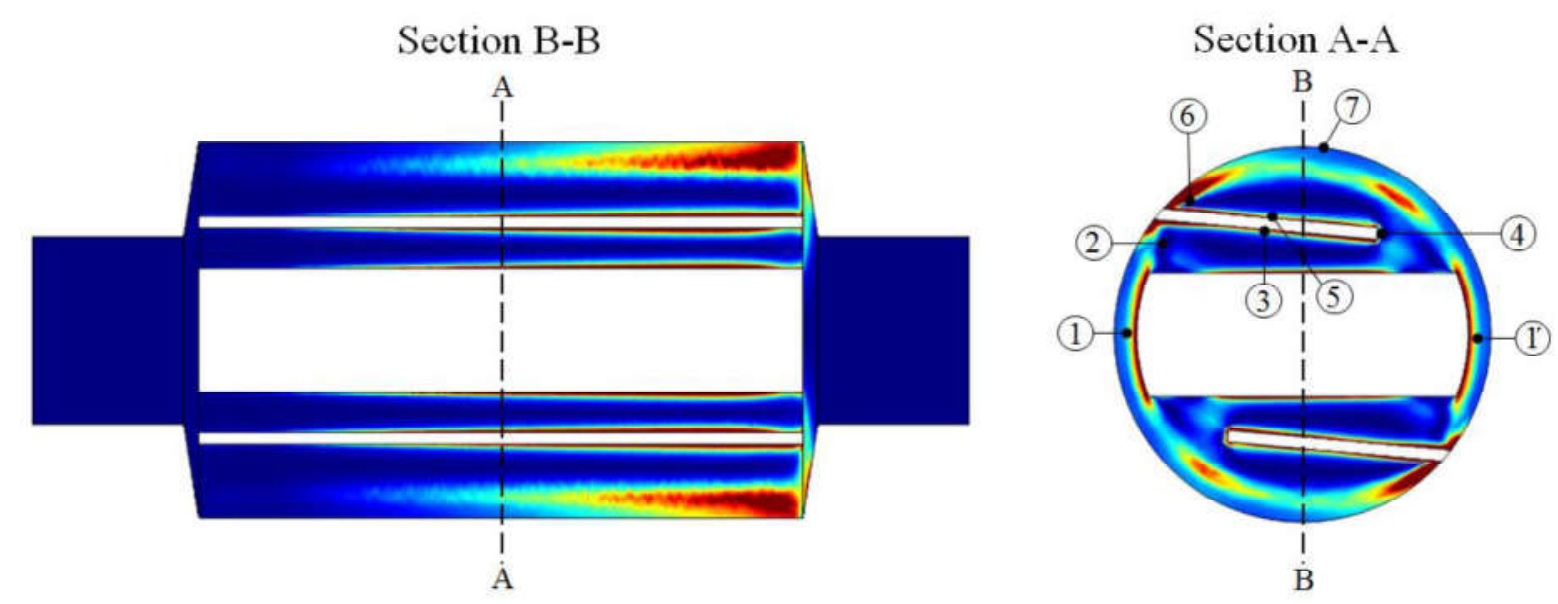

0

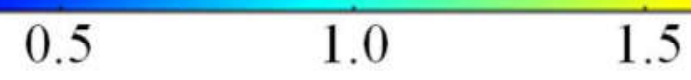

2.0

$2.5 \times 10^{5}$

Figure 8. Views of the profiles in the SSHE as predicted by the numerical model under reference operating conditions: $\dot{m}_{\text {mix }}=50 \mathrm{~kg} / \mathrm{h}, T_{R}=-15.3^{\circ} \mathrm{C}$ and $f_{\text {rot }}=750 \mathrm{rpm}$ :
A) velocity magnitude (top) and shear rate (bottom),
B) pressure,
C) temperature,
D) enthalpy and ice fraction, and
E) viscous dissipation rate. 


\section{FIGURE 9A)}

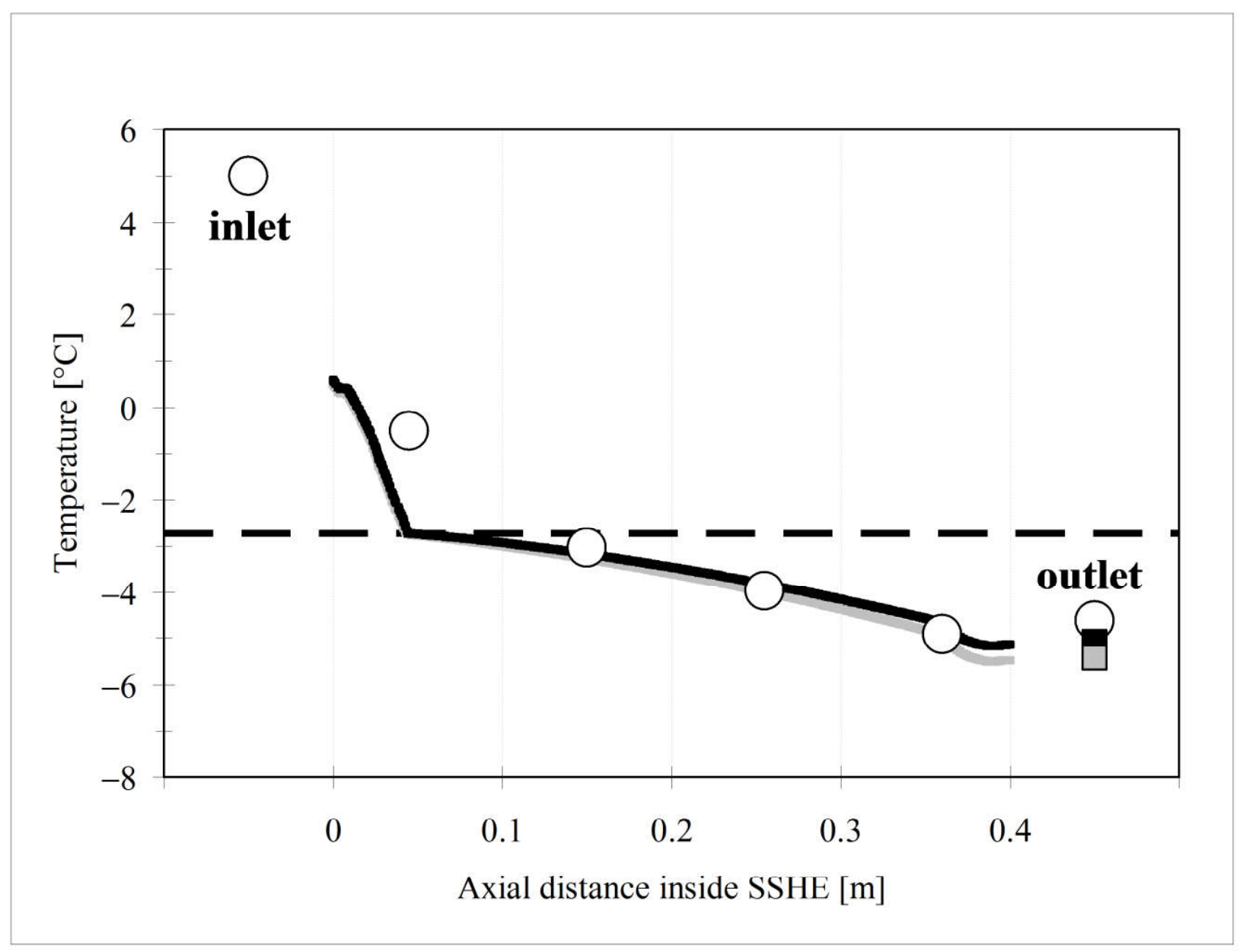




\section{FIGURE 9B)}

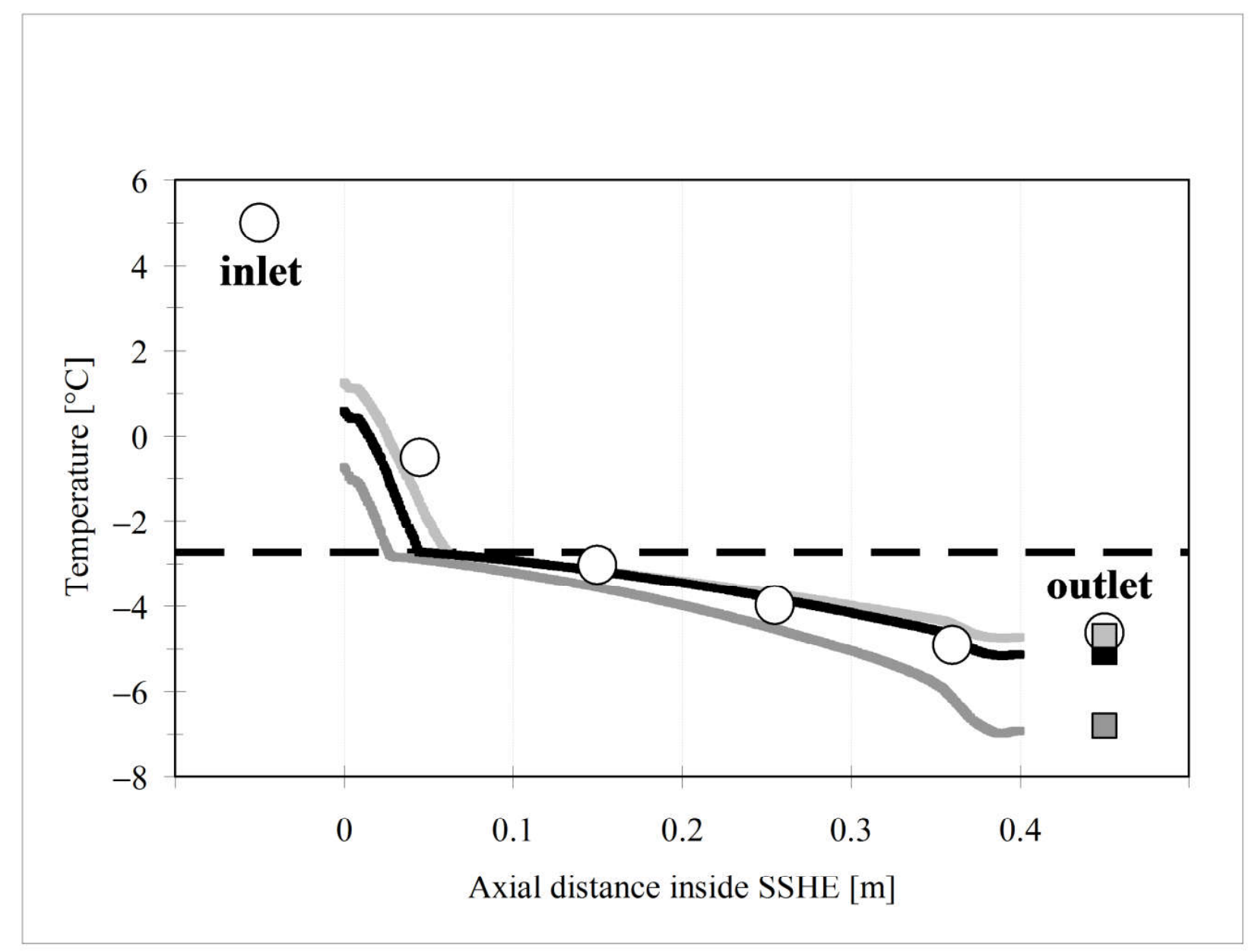

Figure 9. A) Measurements of temperature by Arellano et al. (2013a) at selected positions of the SSHE (circles) and temperature axial profiles predicted by the numerical model under reference operating conditions $\left(\dot{m}_{\text {mix }}=50 \mathrm{~kg} / \mathrm{h}, T_{R}=-15.3^{\circ} \mathrm{C}\right.$ and $f_{\text {rot }}=750 \mathrm{rpm}$ ), after setting the thermal conductivity of solids to $15 \mathrm{~W} \cdot \mathrm{m}^{-1} \cdot \mathrm{K}^{-1}$ (black line) and to zero (grey line). Squares indicate mean surface values of temperature as predicted by the numerical model at the exit of the outlet pipe. The dashed line indicates the initial freezing temperature. B) The same, but setting the heat transfer coefficient at the SSHE inner wall to $2500 \mathrm{~W} \cdot \mathrm{m}^{-2} \cdot \mathrm{K}^{-1}$ (black line), to a value $20 \%$ larger $\left(3000 \mathrm{~W} \cdot \mathrm{m}^{-2} \cdot \mathrm{K}^{-1}\right)$ (dark grey line) and to a value $20 \%$ smaller $\left(2000 \mathrm{~W} \cdot \mathrm{m}^{-2} \cdot \mathrm{K}^{-1}\right)$ (light grey line). 


\section{FIGURE 10)}

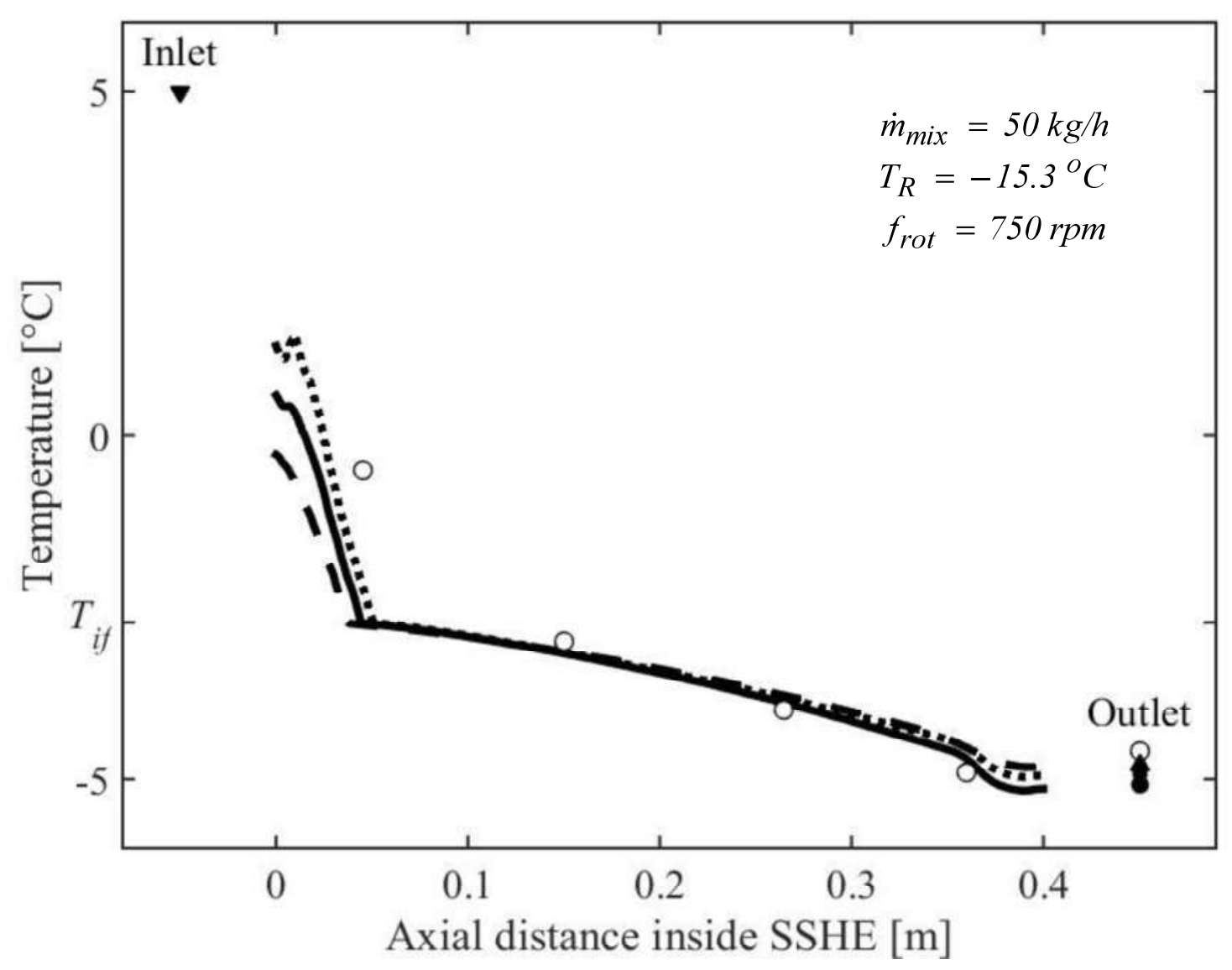

Figure 10. Measurements of temperature by Arellano et al. (2013a) at selected positions of the SSHE (circles) and temperature axial profiles predicted by the numerical model under reference operating conditions $\left(\dot{m}_{m i x}=50 \mathrm{~kg} / \mathrm{h}, T_{R}=-15.3{ }^{\circ} \mathrm{C}\right.$ and $f_{\text {rot }}=750 \mathrm{rpm}$ ), after using three meshes constituted by an increasing number of elements: (--) $6.5 \times 10^{5}$, (-) $1.5 \times 10^{6}$ and $(\cdot-) 3.5 \times 10^{6}$ elements. Corresponding values of the surface-averaged value of predicted temperatures at the exit of the outlet pipe are also indicated, for

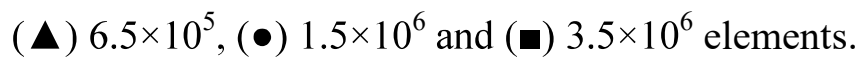




\section{FIGURE 11)}

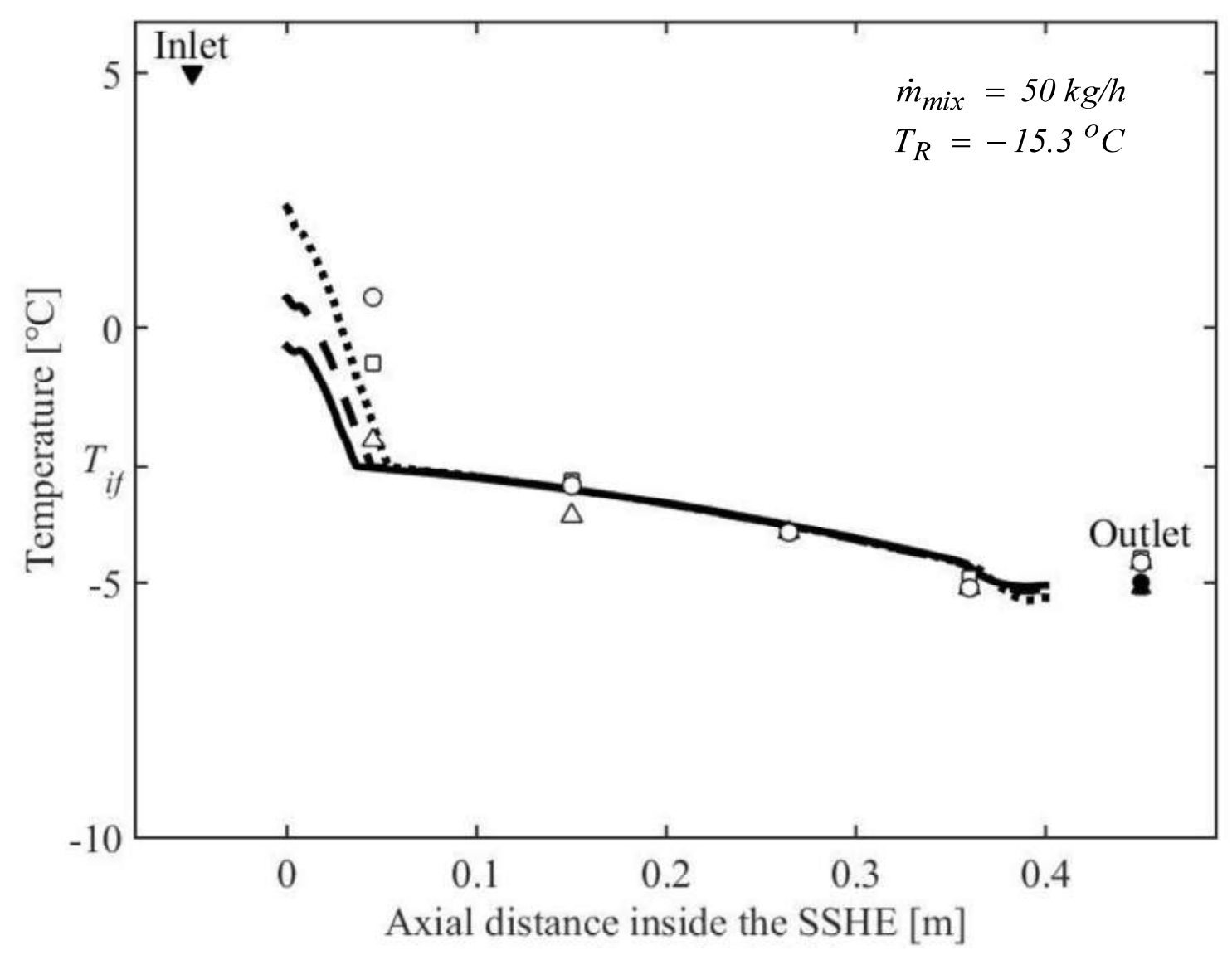

Figure 11. Effect of the dasher rotation frequency on the temperature profile along the exchanger:

$(\boldsymbol{\nabla})$ prescribed value at the inlet, for all the operating conditions $\left(5^{\circ} \mathrm{C}\right)$;

measured values for $(\Delta) f_{\text {rot }}=545 \mathrm{rpm},(\square) f_{\text {rot }}=750 \mathrm{rpm}$, and $(\circ) f_{\text {rot }}=1000 \mathrm{rpm}$;

predicted profiles for $(\boldsymbol{\omega}) f_{\text {rot }}=545 \mathrm{rpm},(--) f_{\text {rot }}=750 \mathrm{rpm}$, and $(-) f_{\text {rot }}=1000 \mathrm{rpm}$; and surface-averaged values at the exit for $(\boldsymbol{\Delta}) f_{\text {rot }}=545 \mathrm{rpm},(\boldsymbol{\bullet}) f_{\text {rot }}=750 \mathrm{rpm}$, and $(\bullet) f_{\text {rot }}=$ $1000 \mathrm{rpm}$. 


\section{FIGURE 12)}

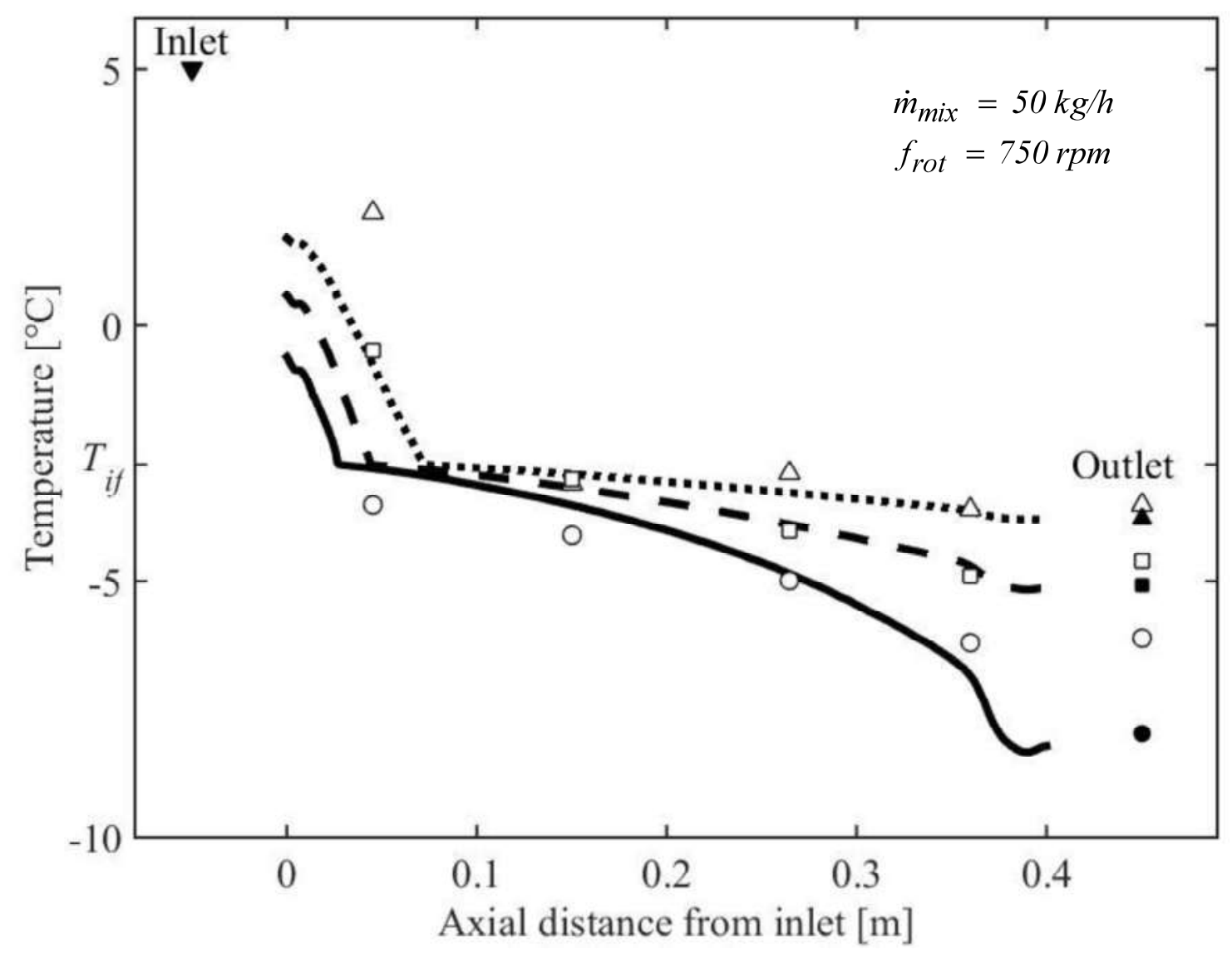

Figure 12. Effect of the refrigerant evaporation temperature on the temperature profile along the exchanger:

( $\boldsymbol{\nabla})$ prescribed value at the inlet, for all the operating conditions $\left(5^{\circ} \mathrm{C}\right)$;

measured values for $(\Delta) T_{R}=-10.3{ }^{\circ} \mathrm{C}$, (口) $T_{R}=-15.3{ }^{\circ} \mathrm{C}$, and $(\circ) T_{R}=-20.1{ }^{\circ} \mathrm{C}$;

predicted profiles for $(\cdots) T_{R}=-10.3{ }^{\circ} \mathrm{C},(--) T_{R}=-15.3{ }^{\circ} \mathrm{C}$, and $(-) T_{R}=-20.1{ }^{\circ} \mathrm{C}$;

and

surface-averaged values at the exit for $(\boldsymbol{\Delta}) T_{R}=-10.3^{\circ} \mathrm{C},(\boldsymbol{\bullet}) T_{R}=-15.3{ }^{\circ} \mathrm{C}$, and $(\bullet) T_{R}$ $=-20.1^{\circ} \mathrm{C}$. 


\section{FIGURE 13)}

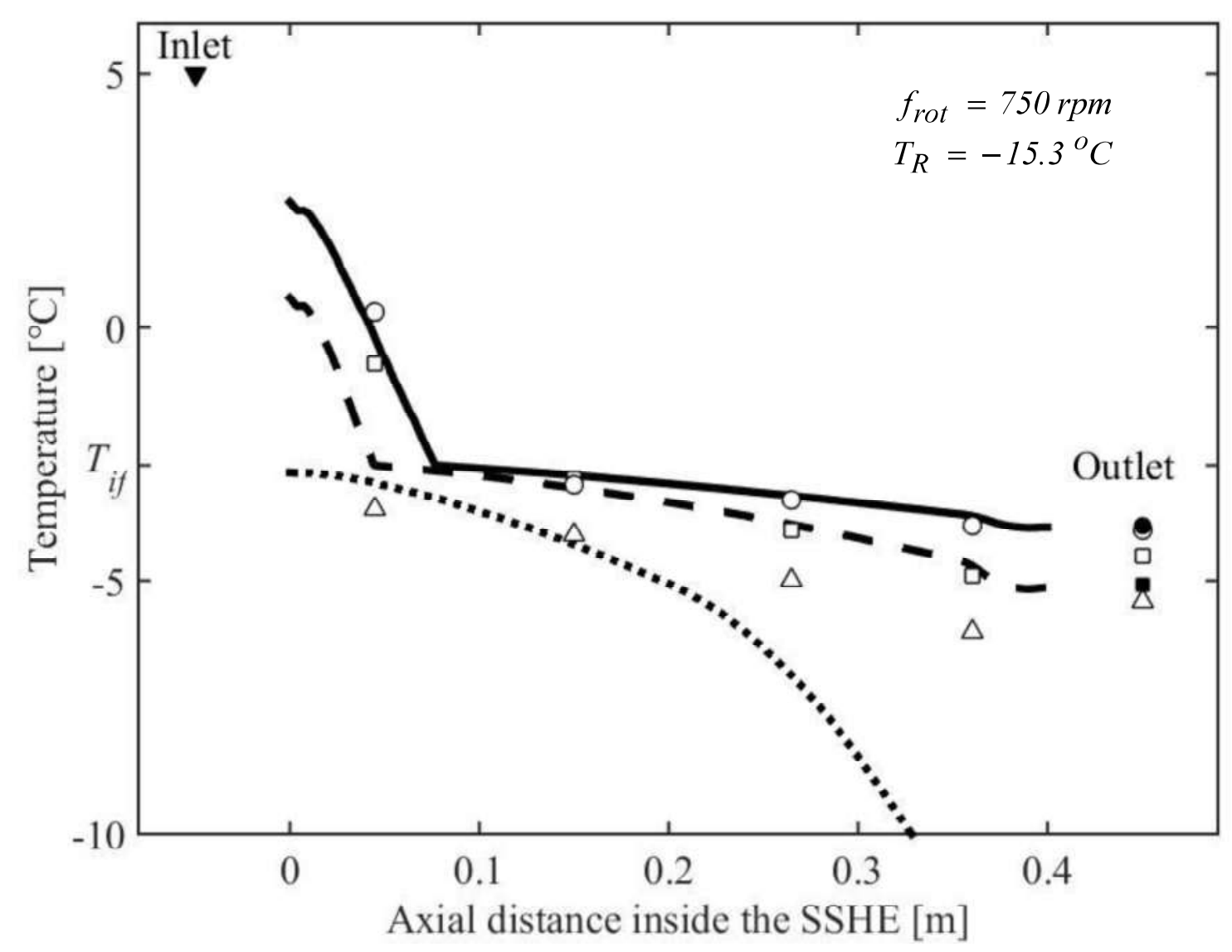

Figure 13. Effect of the mix mass flow rate on the temperature profile along the exchanger:

$(\boldsymbol{\nabla})$ prescribed value at the inlet, for all the operating conditions $\left(5^{\circ} \mathrm{C}\right)$;

measured values for $(\Delta) \dot{m}_{m i x}=25 \mathrm{~kg} / \mathrm{h},(\square) \dot{m}_{m i x}=50 \mathrm{~kg} / \mathrm{h}$, and (०) $\dot{m}_{m i x}=75 \mathrm{~kg} / \mathrm{h}$;

predicted profiles for $\left(\boldsymbol{( - )} \dot{m}_{m i x}=25 \mathrm{~kg} / \mathrm{h},(--) \dot{m}_{m i x}=50 \mathrm{~kg} / \mathrm{h}\right.$, and (一) $\dot{m}_{m i x}=75$

$\mathrm{kg} / \mathrm{h}$; and

surface-averaged values at the exit for $(\bullet) \dot{m}_{\text {mix }}=50 \mathrm{~kg} / \mathrm{h}$ and $(\bullet) \dot{m}_{m i x}=75 \mathrm{~kg} / \mathrm{h}$. 


\section{$1 \quad$ Figure Captions}

2

3 Figure 1. Schematic view of the SSHE pilot unit used for freezing lemon sorbet (Arellano 4 et al., 2013a, 2013b, 2013c):

5 A) $3 \mathrm{D}$ view of the SSHE as represented in the numerical model, and

9 Figure 2. Cross-section view of the SSHE. The computation domain taken into account by

10 the numerical model is pictured in gray (see the whole cross-section view at top-left). This

11 domain is delimited by the thickest line, which corresponds to the internal wall of the

12 SSHE inner cylinder. Other black lines delimitate the SSHE outer and inner cylinders. The

13 wall of the inner cylinder is characterized by thickness $e_{w}$, thermal conductivity $k_{w}$, and

14 the outside and inside temperatures ( $T_{\text {outside }}$ and $T_{\text {nside }}$ respectively). The dashed zone corresponds to the refrigerant fluid, characterized by evaporating temperature $T_{R}$ :

16 solution:

19 (०) obtained experimentally for lemon sorbet mix by Gonzalez Ramirez (2012),

20 (-) estimated for lemon sorbet mix using equation (11),

$21(\Delta)$ obtained experimentally for sucrose solutions by Reiser et al. (2012), and

22 (-) estimated for sucrose using equation (11). 
25 Figure 4. Sorbet physical properties as taken into account in this study:

26 A) ice mass fraction in sorbet according to temperature using equations (9-12);

B) consistency index:

( $\square$ ) obtained experimentally by Arellano et al. (2013b) and

(一) estimated using equation (13);

C) heat capacity:

(-) estimated as proposed by Cogné et al. (2003) and (-) estimated using equations (15);

D) thermal conductivity:

(一) estimated as proposed by Cogné et al. (2003) and (-) estimated using equations (16).

Figure 5. A) Actual cross-section view of the SSHE inlet bowl (left), and its representation in the numerical model (right).

B) The same for the SSHE outlet bow.

Figure 6. Mesh built for the simulations carried out in this work. Right: mesh around the solid elements (dasher and blades); left: cut view in the center of the SSHE inner cylinder.

Figure 7. Velocity field in the SSHE, as predicted by the numerical model under reference operating conditions: $\dot{m}_{m i x}=50 \mathrm{~kg} / \mathrm{h}, T_{R}=-15.3{ }^{\circ} \mathrm{C}$ and $f_{\text {rot }}=750 \mathrm{rpm}$. Velocity vectors presented in the plane $\mathrm{YZ}$ containing the axial direction are not in the same scale than those in the three planes XY crossing the axial direction. 
48 Figure 8. Views of the profiles in the SSHE as predicted by the numerical model under 49 reference operating conditions: $\dot{m}_{\text {mix }}=50 \mathrm{~kg} / \mathrm{h}, T_{R}=-15.3{ }^{\circ} \mathrm{C}$ and $f_{\text {rot }}=750 \mathrm{rpm}$ :

50 A) velocity magnitude (top) and shear rate (bottom),

51 B) pressure,

52 C) temperature,

53 D) enthalpy and ice fraction, and

54 E) viscous dissipation rate.

56 Figure 9. A) Measurements of temperature by Arellano et al. (2013a) at selected positions 57 of the SSHE (circles) and temperature axial profiles predicted by the numerical model 58 under reference operating conditions $\left(\dot{m}_{\text {mix }}=50 \mathrm{~kg} / \mathrm{h}, T_{R}=-15.3{ }^{\circ} \mathrm{C}\right.$ and $\left.f_{\text {rot }}=750 \mathrm{rpm}\right)$, 59 after setting the thermal conductivity of solids to $15 \mathrm{~W} \cdot \mathrm{m}^{-1} \cdot \mathrm{K}^{-1}$ (black line) and to zero 60 (grey line). Squares indicate mean surface values of temperature as predicted by the 61 numerical model at the exit of the outlet pipe. The dashed line indicates the initial freezing 62 temperature. B) The same, but setting the heat transfer coefficient at the SSHE inner wall to $632500 \mathrm{~W} \cdot \mathrm{m}^{-2} \cdot \mathrm{K}^{-1}$ (black line), to a value $20 \%$ larger $\left(3000 \mathrm{~W} \cdot \mathrm{m}^{-2} \cdot \mathrm{K}^{-1}\right)$ (dark grey line) and 64 to a value $20 \%$ smaller $\left(2000 \mathrm{~W} \cdot \mathrm{m}^{-2} \cdot \mathrm{K}^{-1}\right)$ (light grey line).

65 
68 Figure 10. Measurements of temperature by Arellano et al. (2013a) at selected positions of 69 the SSHE (circles) and temperature axial profiles predicted by the numerical model under reference operating conditions $\left(\dot{m}_{\text {mix }}=50 \mathrm{~kg} / \mathrm{h}, T_{R}=-15.3{ }^{\circ} \mathrm{C}\right.$ and $\left.f_{\text {rot }}=750 \mathrm{rpm}\right)$, after

71 using three meshes constituted by an increasing number of elements: (--) $6.5 \times 10^{5}$, (-) $721.5 \times 10^{6}$ and $(\cdot \cdot) 3.5 \times 10^{6}$ elements. Corresponding values of the surface-averaged value of 73 predicted temperatures at the exit of the outlet pipe are also indicated, for

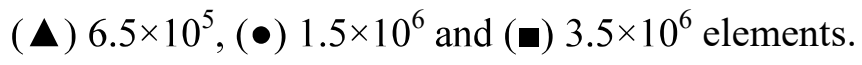

Figure 11. Effect of the dasher rotation frequency on the temperature profile along the exchanger: measured values for $(\Delta) f_{\text {rot }}=545 \mathrm{rpm},(\square) f_{\text {rot }}=750 \mathrm{rpm}$, and $(\circ) f_{\text {rot }}=1000 \mathrm{rpm}$; predicted profiles for $(\boldsymbol{- \cdot}) f_{\text {rot }}=545 \mathrm{rpm},(--) f_{\text {rot }}=750 \mathrm{rpm}$, and $(-) f_{\text {rot }}=1000 \mathrm{rpm}$; and

81 surface-averaged values at the exit for $(\boldsymbol{\Delta}) f_{\text {rot }}=545 \mathrm{rpm},(\boldsymbol{\bullet}) f_{\text {rot }}=750 \mathrm{rpm}$, and $(\bullet) f_{\text {rot }}=$ $82 \quad 1000 \mathrm{rpm}$. 
86 Figure 12. Effect of the refrigerant evaporation temperature on the temperature profile

87 along the exchanger:

88 ( $\boldsymbol{\nabla})$ prescribed value at the inlet, for all the operating conditions $\left(5^{\circ} \mathrm{C}\right)$;

89 measured values for $(\Delta) T_{R}=-10.3{ }^{\circ} \mathrm{C},(\square) T_{R}=-15.3{ }^{\circ} \mathrm{C}$, and $(\circ) T_{R}=-20.1{ }^{\circ} \mathrm{C}$;

90 predicted profiles for $(\cdots) T_{R}=-10.3{ }^{\circ} \mathrm{C},(--) T_{R}=-15.3{ }^{\circ} \mathrm{C}$, and (-) $T_{R}=-20.1{ }^{\circ} \mathrm{C}$;

91 and

92 surface-averaged values at the exit for $(\boldsymbol{\Delta}) T_{R}=-10.3{ }^{\circ} \mathrm{C},(\boldsymbol{\bullet}) T_{R}=-15.3{ }^{\circ} \mathrm{C}$, and $(\bullet) T_{R}$ $93=-20.1^{\circ} \mathrm{C}$.

94

95 Figure 13. Effect of the mix mass flow rate on the temperature profile along the exchanger:

96 ( $\boldsymbol{\nabla})$ prescribed value at the inlet, for all the operating conditions $\left(5^{\circ} \mathrm{C}\right)$;

97 measured values for $(\Delta) \dot{m}_{m i x}=25 \mathrm{~kg} / \mathrm{h},(\square) \dot{m}_{m i x}=50 \mathrm{~kg} / \mathrm{h}$, and (०) $\dot{m}_{m i x}=75 \mathrm{~kg} / \mathrm{h}$;

98 predicted profiles for (--) $\dot{m}_{m i x}=25 \mathrm{~kg} / \mathrm{h},(--) \dot{m}_{m i x}=50 \mathrm{~kg} / \mathrm{h}$, and (一) $\dot{m}_{\text {mix }}=75$

$99 \mathrm{~kg} / \mathrm{h}$; and

100 surface-averaged values at the exit for $(\bullet) \dot{m}_{m i x}=50 \mathrm{~kg} / \mathrm{h}$ and $(\bullet) \dot{m}_{m i x}=75 \mathrm{~kg} / \mathrm{h}$. 
2 Table 1. Physical properties of the sorbet and sorbet mix used in this work 3

\begin{tabular}{|c|c|}
\hline Property & Value or expression \\
\hline \multicolumn{2}{|c|}{ Sorbet } \\
\hline Density & $1050 \mathrm{~kg} \mathrm{~m}^{-3}$ \\
\hline Power-law flow index, $n$ & 0.5 \\
\hline Power-law consistency index, $K$ & equation (13) \\
\hline Heat capacity, $C_{P}$ & equation (15) \\
\hline Thermal conductivity, $k$ & equation (16) \\
\hline \multicolumn{2}{|c|}{ Steel } \\
\hline Thermal conductivity, $k_{w}$ & $15 \mathrm{~W} \mathrm{~m}^{-1} \mathrm{~K}^{-1}$ \\
\hline
\end{tabular}

4 


\section{$1 \quad$ Nomenclature}

2

$3 A_{\text {wall }}$ : heat exchange area $\left(\mathrm{m}^{2}\right)$

$4 \quad c_{p i}:$ ice heat capacity $\left(\mathrm{J} \cdot \mathrm{mol}^{-1} \cdot \mathrm{K}^{-1}\right)$

$5 \quad c_{p w}:$ water heat capacity $\left(\mathrm{J} \cdot \mathrm{mol}^{-1} \cdot \mathrm{K}^{-1}\right)$

$6 C, C_{1}, C_{2}$ : dimensionless parameters

$7 \quad C_{p}$ : apparent specific heat capacity $\left(\mathrm{J} \cdot \mathrm{kg}^{-1} \cdot \mathrm{K}^{-1}\right)$

$8 \quad C_{p i}:$ specific heat capacity of ice $\left(\mathrm{J} \cdot \mathrm{kg}^{-1} \cdot \mathrm{K}^{-1}\right)$

$9 C_{p s}:$ specific heat capacity of solute $\left(\mathrm{J} \mathrm{kg}^{-1} \cdot \mathrm{K}^{-1}\right)$

$10 C_{p w}:$ specific heat capacity of water $\left(\mathrm{J} \cdot \mathrm{kg}^{-1} \cdot \mathrm{K}^{-1}\right)$

$11 e_{w}$ : wall thickness of the SSHE inner cylinder (m)

$12 f_{\text {rot }}$ : frequency of rotation (rev/s)

$13 h_{\text {outside }}$ : heat transfer coefficient, external side of SSHE inner wall $\left(\mathrm{W} \cdot \mathrm{m}^{-2} \cdot \mathrm{K}^{-1}\right)$

$14 \hat{H}_{\text {inlet }}, \hat{H}_{\text {outlet }}$ : specific enthalpies at SSHE inlet and outlet $\left(\mathrm{J}_{\mathrm{kg}} \mathrm{kg}^{-1}\right)$

$15 k$ : thermal conductivity of product $\left(\mathrm{W} \cdot \mathrm{m}^{-1} \cdot \mathrm{K}^{-1}\right)$

$16 k_{w}$ : thermal conductivity of stainless steel wall $\left(\mathrm{W} \cdot \mathrm{m}^{-1} \cdot \mathrm{K}^{-1}\right)$

$17 K$ : consistency index $\left(\mathrm{Pa} . \mathrm{s}^{\mathrm{n}}\right)$

$18 \dot{m}$ : mass flow rate $\left(\mathrm{kg} . \mathrm{s}^{-1}\right)$

$19 M_{S}$ : molar mass of solute $\left(\mathrm{kg} \cdot \mathrm{mol}^{-1}\right)$

$20 M_{w}$ : molar mass of water $\left(\mathrm{kg} \cdot \mathrm{mol}^{-1}\right)$

$21 n$ : flow behavior exponent (-) 
$p:$ pressure $(\mathrm{Pa})$

$23 \vec{q}$ : conductive heat transfer vector $\left(\mathrm{W} . \mathrm{m}^{-2}\right)$

$24 \vec{r}$ : position vector

$25 \quad r$ : radial component of the position vector $(\mathrm{m})$

$26 r_{\text {pipe }}$ : pipe radius (heat exchanger cylinder) (m)

$27 R$ : ideal gas constant $\left(8.314 \mathrm{~J} \cdot \mathrm{mol}^{-1} \cdot \mathrm{K}^{-1}\right)$

$28 T$ : temperature $(\mathrm{K})$

$29 T_{\text {if }}$ : initial freezing temperature $(\mathrm{K})$

$30 T_{m p}$ : pure-water melting-point temperature $(\mathrm{K})$

$31 T_{R}$ : refrigerant evaporating temperature $(\mathrm{K})$

$32 U$ : global heat transfer coefficient $\left(\mathrm{W} \cdot \mathrm{m}^{-2} \cdot \mathrm{K}^{-1}\right)$

$33 \vec{u}$ : velocity vector in the Galilean frame $\left(\mathrm{m} \cdot \mathrm{s}^{-1}\right)$

$34 \vec{v}$ : velocity vector in the rotating frame $\left(\mathrm{m} . \mathrm{s}^{-1}\right)$

$35 w_{i}$ : ice mass fraction $(-)$

$36 w_{s}$ : solute mass fraction $(-)$

$37 w_{s 0}$ : initial solute mass fraction, at the exchanger inlet (-)

$38 w_{s}^{*}$ : solute mass fraction at saturation $(-)$, see eq. (9)

$39 x_{w}$ : water molar fraction at saturation $(-)$

$40 \quad z$ : axial component of the position vector $(\mathrm{m})$

41

42 
43 Greek symbols

44

$45 \Delta h_{f, m p}$ : ice-water heat of fusion $\left(\mathrm{J} . \mathrm{mol}^{-1}\right)$, see eq. (9)

$46 \Delta H_{f}$ : specific heat of fusion of ice $\left(\mathrm{J}^{\mathrm{kg}} \mathrm{kg}^{-1}\right)$, see eq. (14)

$47 \vec{\Omega}_{\text {rotor }}:$ angular velocity vector $\left(\operatorname{rad} . \mathrm{s}^{-1}\right)$

$48 \rho:$ density $\left(\mathrm{kg} \cdot \mathrm{m}^{-3}\right)$

$49 \overline{\bar{\tau}}$ : viscous stress tensor $(\mathrm{Pa})$ 